\title{
Review \\ Building Geometry as a Variable in Energy, Comfort, and Environmental Design Optimization-A Review from the Perspective of Architects
}

\author{
István Kistelegdi ${ }^{1} \mathbb{D}$, Kristóf Roland Horváth ${ }^{1, *}$, Tamás Storcz ${ }^{2} \mathbb{D}$ and Zsolt Ercsey ${ }^{2} \mathbb{D}$ \\ 1 Energia Design Research Group, Department of Building Structures and Energy Design, \\ Faculty of Engineering and Information Technology, János Szentágothai Research Centre, \\ University of Pécs, 7624 Pécs, Hungary; kistelegdisoma@mik.pte.hu \\ 2 Department of Systems and Software Technology, Faculty of Engineering and Information Technology, \\ University of Pécs, 7624 Pécs, Hungary; storcz.tamas@mik.pte.hu (T.S.); ercsey.zsolt@mik.pte.hu (Z.E.) \\ * Correspondence: kristofrol@gmail.com
}

check for updates

Citation: Kistelegdi, I.; Horváth, K.R.; Storcz, T.; Ercsey, Z. Building Geometry as a Variable in Energy, Comfort, and Environmental Design Optimization-A Review from the Perspective of Architects. Buildings 2022, 12, 69. https://doi.org/ 10.3390 /buildings12010069

Academic Editor: Gerardo Maria Mauro

Received: 9 November 2021 Accepted: 29 December 2021 Published: 12 January 2022

Publisher's Note: MDPI stays neutral with regard to jurisdictional claims in published maps and institutional affiliations.

Copyright: (C) 2022 by the authors. Licensee MDPI, Basel, Switzerland. This article is an open access article distributed under the terms and conditions of the Creative Commons Attribution (CC BY) license (https:// creativecommons.org/licenses/by/ $4.0 /)$.

\begin{abstract}
Due to negative environmental impacts caused by the building industry, sustainable buildings have recently become one of the most investigated fields in research. As the design technique itself is mainly responsible for building performance, building energy design optimization is of particular interest. Several studies concentrate on systems, operation, and control optimization, complemented by passive strategies, specifically related to the envelope. In building physics, different architectural considerations, in particular, the building's shape, are essential variables, as they greatly influence the performance of a building. Most scientific work that takes into consideration building geometry explores spaces without any energy optimization or calculates optimization processes of a few basic variables of simplified space geometries. Review studies mainly discuss the historic development of optimization algorithms, building domains, and the algorithm-system and software framework performance with coupling issues. By providing a systemized clustering of different levels of shape integration intensities, space creation principals, and algorithms, this review explores the current status of sustainability related shape optimization. The review proves that geometry design variable modifications and, specifically, shape generation techniques offer promising optimization potential; however, the findings also indicate that building shape optimization is still in its infancy.
\end{abstract}

Keywords: building shape optimization; building geometry design variables; energy efficiency; comfort performance; building physics simulation; optimization algorithm; design method

\section{Introduction}

The 2019 Global Status Report for Buildings and Construction warns that the building sector is not on track to meet the United Nations (UN) Sustainable Development Goals (SDGs), and that building stock is set to double by 2050. The energy efficiency improvements in the building sector slowed to less than $50 \%$ of the average rate since 2010 [1]. Approximately $44 \%$ of the final energy use and $40 \%$ of the $\mathrm{CO}_{2}$ emissions are rooted in the construction and operation of buildings [1,2], and approximately 50\% of office and residential buildings' operation consumption is due to HVAC demand $[3,4]$. Due to a growing population, and more households and floor space, an increase by approximately $28 \%$ is predicted by 2035. Although the design process and construction method is primarily responsible for the sustainability performance of buildings constructed, the prevailing conventional design method in industry relies almost completely on experience and includes only a limited number of concepts.

Because architects focus primarily on the artistic side of design, they are not taught how to handle engineering and mathematical calculations. The architect's plan is created as a first step, and engineers define and size the mechanical and electrical systems to supply 
the comfort and energy requirements for the building. Interaction between the disciplines and the iterative design adjustments are reduced to as few as possible, which unfortunately means that optimal design of form, materials, and systems is not ensured [5]. Typically, it is the building services system engineer who is responsible for the energy performance of a project, mainly through improving the HVAC systems. At the same time, they are not trained with the necessary building design skills, even though it is the main determining factor for all comfort and energy tasks. Even though an architect does not receive deep training in building physics, they bring the greatest weight into energy efficiency and other sustainable building performance of a project. As leader of the planning team, the architect creates the DNA code of the building, the space organization and the buildings shape. These fundamental design features have a major contribution to the energy performance [6,7], while subsequent decisions at later further stages, which take into consideration the envelope, structures, etc., also influence various factors of energy design. For this reason, it is imperative that energy optimization should be mainly managed by architects.

In sustainable building design, multiple objectives, influencing variables, and constraints drive the problem-solving process, and these functions are often contradictory. To handle this problem, various building design optimization methods have been developed. 'Parametric simulation method' is a common building energy, comfort, and environmental design optimization (BECEDO) technique. It tries to optimize only one design variable at a time by testing the effects of changing the variable, while the remaining variables are kept constant. This time- and work-consuming method is only able to improve partially due to non-linear interrelationships between variables and outputs. In architecture, a relatively new, promising method is represented by 'simulation-based or numerical optimization' processes: the automated coupling of numerical simulations and mathematical optimization algorithms. Based on iterative, 'infinite' calculation sequences, more exact approximation results are achieved to a solution or point at most possible proximity (near optimum) in the search space, satisfying the objective function [8]. In order to achieve a level of BECEDO (i.e., to reach the desired performance) finding the minimum or maximum value of a cost, fitness or objective function is necessary, by choosing and modifying particular design variables subject to different constraints [8].

According to estimations [9], optimization of the building envelope and the HVAC system has a potential for $20-60 \%$ energy conservation. Improvements in artificial lighting are predicted to reduce energy demand by $20-70 \%$, which is also similar for refrigeration and hot water generation optimization. Intelligent controlling of the systems and electric equipment contributes to a further 10-20\% efficiency [10]. Apparently, there are no existing estimations in the literature about the energy saving potential of optimized space organization and shape forming of buildings. In addition, only a few studies discuss how architects consider the engineering optimization procedure and how the technique could be built in the general planner's (architect) design method [9].

The first BECEDO publication dates back to the beginning of the 1970s [11], but the number of publications has grown considerably since $2000[8,9,12]$. Most of the in-depth analysis of optimization algorithms is provided in non-architectural fields, such as IT, mathematics, and operation technologies. BECEDO studies are significantly less than the number of research in operation control optimization [13], and only approximately $30 \%$ of the studies applied their technique on real-world buildings [9]. Furthermore, much of the existing research focuses on the technique itself (e.g., developing and coupling algorithms and calculation engines, integrating surrogate models, etc.) and its application to an oversimplified building example to validate the functionality of the proposed method. In recent years, remarkable improvements have been made in the automation of modelling, co-simulation, evaluation, and coupling optimization algorithms with calculation engines (interoperability). Utilizing hybrid algorithms, meta-models, parallel and cloud computing, adaptive fitness coarseness, simplification of the building model, or assessment tools is effective in reducing computation time for faster convergence [12]. A number of review studies systemize BECEDO research in terms of historic development of optimization algorithms, 
building domains, design variables, objective function and constraints, as well as analysis of the algorithm-system performance and software framework with coupling issues $[8,9,12,13]$.

In passive systems, studies specifically modify the main design variables of the opaque and transparent envelope structures and materials, e.g., the thicknesses and thermal properties of the insulation and walls, as well as wall-window ratios (WWR), orientation, materials, structures, and shading, for instance [14-21]. Another group of studies concentrates on the design variables of the HVAC and energy system and the combination variables of active (mechanical) systems and passive (architectural) strategies, e.g., envelope material properties, and operation and control [14,22-36]. In urban contexts, the optimization of the façade PV-panel system density and arrangement is carried out for maximizing solar energy usage and level of visual comfort (sDA) in a city district with diverse dense and high building arrangement [37]. The focus in these studies is set on demonstrating and validating the optimization model and the algorithms through a simplified example with very specific results of particular case studies. The results are typically lacking in terms of building physics. Although utilizing an increasing number of design variables, they are limited to engineering systems, materials, and structures and leave out the space organization and building shape variables.

At the same time, the building shape is an essential BECEDO performance affecting design variable too $[6,7,26,38-49]$. A comprehensive review [12] on energy efficient building geometry and building envelope design concludes after analysis of around 400 related publications, that building shape and envelope design substantially affect the energy performance. A typical shortcoming in previous studies is that most of them focus on the optimization technique itself, as well as quantifiable variables and objective functions, without integrating other objectives of related building design disciplines. Building envelope and shape are potentially variable groups for energy conservation through passive and active strategies in general [12]. The motto of 'Form follows energy' and 'Form follows performance' emphasize that building form is a decisive factor of energy efficiency and has become a 'dogma' over the last decade. Implementation, however, remains a complex challenge. Although building form has significant impact on building operation maintenance cost that exceeds in several orders the initial investment, there exist no generic guidelines for architects about the relationship between shape and energy efficiency [50]. In [5], 64 diverse building geometries were investigated in their architectonical form-language and solar gain in relation to maximized solar energy production surface vs. minimized heat loss through the envelope (min-max antagonistic problem). A new factor of form efficiency is proposed to quantify the concentration of solar energy on a building surface form in a given climate. The author indicates that only a few investigations have been carried out experimenting with formal design in architecture and urban planning, though over $100 \%$ increase in solar gains are possible due to optimized geometry. A discussion [51] points out the limited utilization of building geometry in research of energy-efficient design: it emphasizes that while some optimization studies may go too far into formal investigation by generating impractical complex forms [38], other studies adopt extremely simple shapes, hardly touching the depth of potential [50]. It concludes that the omission of geometry from the discussion of energy performance and the limited understanding of the energy relation of formal design aspects represents a crucial research gap. Geometry not only influences operation energy and energy production, but it also has a strong effect on structural design, a crucial field in embedded energy demand. In [52], a knowledge gap is proposed through documenting and codifying the implicit interpretations of architectural design models for structural analysis models making efficient structural design (material demand) possible. The proposed method reduces the dimensionality of geometries and structures and then reconnects the elements to create geometrical interpretations. The data exchange can be significantly simplified by automating the interpretations process, leaving some building elements and geometries to structural engineers to deal with.

Previous work treats building shape in building energy, comfort, and environmental design (BECED) research by demonstrating how building geometry measures modify and 
improve energy efficiency and how shape design variables are dependent on a variety of climate conditions and the surrounding natural or urban context. A simplified analysis method (correlation equation) is elaborated in [7] based on whole-year detailed simulations to estimate how building geometry affects energy efficiency of office buildings in Kuwait. The results underline the strong effect of geometry, WWR, and glazing type on energy efficiency. Another study conducts a comprehensive sensitivity analysis that explores the energy effects of basic building geometry, examining the aspect ratio, roof shape, building height (stacking), WWR, orientation, eaves, and further thermal aspects of materials in four climates [46]. It was concluded that aspect ratio and stacking fundamentally influence the energy performance of residential buildings. The importance of the geometry (optimized energy performance and creative nature of architectural design) is also underlined in a further interesting study [39] by dividing the complete investigation into two consecutive phases: firstly, geometry optimization, and thereafter passive and active system optimization. The authors of [53] integrate urban block form, size and perimeter to area ratio, and spacing between the residential blocks into an exergy load improving investigation, but a reasonable description of the building geometry as a design variable (BGDV) consideration is missing. Validated via laboratory measurements, [6] underlines the importance of geometry in 14 different building shapes, investigated in diverse climates. The results reveal that compactness is important in cold climates and has less significance in mild/warm climates. In multi-story building scenarios [48] intended to minimize heating demand, the most advantageous SF is 1:1 (square), whereas for heating efficiency SF of 1:1 and 2:1 with S, ORI perform best, and the most appropriate ORI for SF of 1:2 is SW. A simplified correlation (regression analysis) tool is proposed in [43] to assess the impact of building shape on cooling and total annual energy use for office buildings. According to the results, the higher the RC, the lower the cooling and total energy demand. Other research [47] focuses on solar energy utilization by modifying simple shape, density, and site layout parameters of two-story residential buildings in different neighborhoods. The active roof surface is most influential as a consequence of ORI and the shape of facades, providing up to $50 \%$ increase in electricity generation relative to rectangular layout. What is in common with all these studies is that the geometry versions are created by modifying a base shape, i.e., one or more dimensional parameters are changed in order to transform an initial shape into new building body forms.

Another group of BECED studies produces building shape versions according to specific techniques and rules by generating diverse geometries from bottom up. A converted shape grammar system [54] provides a generative design system with "if" / "then" rules to produce building geometries by arranging rooms, corners, and porches together. After presenting the method, relevant rules were disregarded (simplifications) in the proposed application, demonstrating diverse family house forms and shape coefficients (surface envelope to indoor volume ratio A/V) with largely differing floor areas. The study did not reflect a regular architectural task that, in most cases, possesses a strictly predefined net floor space size, determined by the client and/or by regulations. Additionally, the method is limited in shape handling. In a further work, 96,000 family houses were generated [55] to analyze the energetic relationship between six compactness and window-based variables and the U-value of the envelope in eight European climates. The conclusion stated that lowering U-values decreases the impact of geometry and WWR in colder climate zones, and in warmer climates, overheating inverts this tendency. Though comprehensive, no optimization is carried out here, and the impacts of geometry were not fully studied: shapes and $U$-values were randomly generated in a large number to detect a general trend, rather than to understand energy-based relationships to specific geometries. Moreover, increasing the thermal properties of the envelope requires extra investment cost and LCA impact [22] and neglects the significant energy intensity of the building shape [6,7,26,43-48]. Other work investigates the impacts of urban neighbor building morphology on cooling load and natural ventilation potential of a 12-story target building in a hot-arid climate [56]. A 'Building Modular Cell' (BMC) technique is introduced to generate urban structure, based on a 
$5 \times 5$ grid raster with five different urban density (UD) building categories, three building height classes, and five urban pattern ranges (street area between the building blocks) and a form generation algorithm (including architecturally eligible form selection). This research demonstrated that normal UD (50-60\% site coverage) require low-rise neighbor buildings, and high UD is required to decrease cooling demands. L-shape is preferred, and push-and pull on the east side in the layout enables cooling reduction. It is recommended to have a dense neighborhood with low street width, and the ratio of building height to street width $(\mathrm{H} / \mathrm{W})$ should be 12 or higher, whereas for best natural ventilation potential, $\mathrm{H} / \mathrm{W}$ 6-8 should be considered. Typically, these BECED investigations lack in mathematical optimization methods; nevertheless, they often provide the automated creation of geometry variants, combined with simulation-based evaluation; thus, they represent an important step towards BGDV optimization.

The majority of real-world BECEDO cases focus on refurbishment projects, partly due to the large scale of the existing built environment in developed countries, and due to the fact that, in renovation tasks, the shape is typically fixed, making it unnecessary to deal with issues resulting from complicated differences in form [9].

Regarding the spectrum of previous scientific work that integrates BGDV-s into optimization containing BECEDO processes, a relatively large number of publications provide promising article titles, including "shape optimization" and similar terms. However, after analysis, it becomes clear that, in most of these investigations, the exact role, measurements, and effect of geometrical aspects remain unclear (see Sections 3 and 4). The studies process geometry-related issues in diverse levels of significance, whereas a complex picture evolves only with a large diversity of the used objective functions such as building types and sizes, climates, BGDV-s, algorithms, methods, and simulation and programming techniques. Specifics about how the results can be practically incorporated into further design are not clarified. Therefore, the current review intends to provide a clear overview of existing literature with a systemized classification of BGDV integration BECEDO research, including the role and state-of-the-art performance of this complicated and important variable system in building energy design optimization. After scanning the existing literature, and according to the knowledge of the authors, no review analysis currently exists in this domain. The main driving force of this particular analysis and discussion is to extract the status quo of previous work by answering the following questions:

- What kind of BGDV-s exists in current BECEDO research?

- What are the roles and functions of the different BGDV-s in BECEDO investigations?

- What are the frequently applied simulation engines, optimization algorithms, and software frameworks (including the diverse methods) in BECEDO?

- What kind of space organization and shape defining solutions exist, and what are the pros and cons of each process?

- Which type of building performance is improved through BGDV-s, and how large is the impact on the improvements?

- Is it possible to create a link between the concrete building form and its geometry describing mathematical design variables? Where is the level of achievement in actual research to replicate shape with the use of BGDV-s?

- What is the potential of building shape optimization?

- How can the achieved results and knowledge be applied in further design projects?

- What kind of limitations and/or shortcomings can be detected?

\section{Geometry as a Design Variable in BECEDO}

\subsection{Building Geometry Variables on Basic Level of Complexity}

For decades, studies have concentrated on automated building space and geometry generation without considering building physics performance [57-60] or mathematical optimization. However, there is available literature about BECEDO research work, considering energy related design variables of the building shape. To gain a clear overview of the available studies, a chronological database was established (Table 1). 
Table 1. BECEDO research using basic building shape design variables

\begin{tabular}{|c|c|c|c|c|c|c|c|}
\hline Ref. No. & Year & Topic and Achievements & Objective Function & $\begin{array}{l}\text { Building Geometry Design } \\
\text { Variables }\end{array}$ & $\begin{array}{l}\text { (a) } \\
\text { (b) } \\
\text { (c) }\end{array}$ & $\begin{array}{l}\text { Algorithm } \\
\text { Simulation Engine } \\
\text { Framework/Method }\end{array}$ & Limitations \\
\hline [50] & 2019 & $\begin{array}{l}\text { MO optimization of office building energy } \\
\text { performance and daylight optimization against DOE } \\
\text { commercial reference building template. Climate } \\
\text { effect on daylight and energy performance in } \\
\text { early-stage design. Depth of the building is greatly } \\
\text { influenced by the climate. In hot and mixed climate, } \\
\text { larger aspect ratios (1.97) are better, while in cold } \\
\text { climates, lower aspect ratios (1-1.37) are } \\
\text { advantageous. Roof ridge should be located around } \\
\text { the center of the building. Most influencing design } \\
\text { variables on EUI and UDI are skylights and windows } \\
\text { and some shading properties. Building depth } \\
\text { strongly determines the energy demand. }\end{array}$ & $\begin{array}{ll}\text { - } & \text { Max. useful daylight } \\
\text { Illuminance (UDI) } \\
\text { Min. energy use intensity } \\
\text { (EUI) }\end{array}$ & $\begin{array}{ll}\text { - } & \text { Depth of space/building } \\
\text { - } & \text { wing } \\
\text { Roof slope/eave/ridge } \\
\text { location } \\
\text { - GR, ORI, STR, TM, SHADE }\end{array}$ & $\begin{array}{l}\text { (a) } \\
\text { (b) } \\
\text { (c) }\end{array}$ & $\begin{array}{l}\text { MOGA } \\
\text { EnergyPlus } \\
\text { GH, Ladybug, Honeybee, } \\
\text { Octopus, R }\end{array}$ & $\begin{array}{l}\text { Very limited } \\
\text { geometry-related design } \\
\text { variables. GA; hence, only } \\
\text { near-optimal solutions. } \\
\text { Conclusions about building } \\
\text { physics performance are not } \\
\text { new. Definition of } \\
\text { generation and population } \\
\text { sizes are not justified. }\end{array}$ \\
\hline [61] & 1987 & $\begin{array}{l}\text { Pioneer study from the 1st authors (1983) } \\
\text { investigating building energy optimization including } \\
\text { shape and envelope variables. Office }\left(2000 \mathrm{~m}^{2}\right) \text {. } \\
\text { Exemplary demonstration of the method. }\end{array}$ & $\begin{array}{ll}\text { - } & \text { Min. thermal load } \\
\text { - } & \text { Total capital cost } \\
& \text { Max. area ratio, } \\
& \text { performing appropriate } \\
\text { illumination level }\end{array}$ & $\begin{array}{ll}\text { - } & \text { Floor space } \\
\text { - } & \text { Aspect ratio } \\
& \text { Significant geometry } \\
& \text { modification } \\
\text { - } & \text { Height/stacking } \\
\text { - } & \text { GR, ORI, STR, TM, SHADE } \\
\text { HVAC/energy system }\end{array}$ & (c) & $\begin{array}{l}\text { Pareto optimal dynamic } \\
\text { programming, FORTRAN }\end{array}$ & $\begin{array}{l}\text { Without simulation and } \\
\text { advanced optimization } \\
\text { algorithm. }\end{array}$ \\
\hline [62] & 2001 & $\begin{array}{l}\text { Building envelope optimization in sketch plan stage } \\
\text { for family house in variable size-an interactive tool. } \\
\text { Multiple criteria decision aid procedure (MCDA), } \\
\text { integrating the client, design team, public authorities } \\
\text { and users preferences, requirements, and constraints } \\
\text { into the optimization process. (1) Definition of } \\
\text { constraints and objectives, (2) feasibility study, (3) } \\
\text { sketch design. Iterative intervention/optimization is } \\
\text { carried out considering all participants requirements, } \\
\text { performance results and design. }\end{array}$ & $\begin{array}{ll}\text { - } & \text { Min. heating cost } \\
\text { - } & \text { Min. AC cost } \\
\text { - } & \text { Min. DHW cost } \\
\text { - } & \text { Minh. operating cost } \\
& \text { Min. construction } \\
& \text { investments }\end{array}$ & $\begin{array}{ll}\text { - } & \text { Aspect ratio } \\
\text { - } & \text { Geometry generation with } \\
\text { energy evaluation } \\
\text { - } & \text { Roof slope/eave/ridge } \\
& \text { location } \\
\text { - } & \text { GR, ORI, STR, TM, SHADE } \\
\text { - HVAC/energy system }\end{array}$ & $\begin{array}{l}\text { (a) } \\
\text { (b) } \\
\text { (c) }\end{array}$ & $\begin{array}{l}\text { GA } \\
\text { LEMA EsQUIsE module } \\
\text { Aid to the multiple } \\
\text { criteria conception of the } \\
\text { building envelope } \\
\text { (AMCE) }\end{array}$ & $\begin{array}{l}\text { GA; hence, only } \\
\text { near-optimal solutions. } \\
\text { Only theoretical proposal. }\end{array}$ \\
\hline
\end{tabular}


Table 1. Cont.

\begin{tabular}{|c|c|c|c|c|c|c|c|}
\hline Ref. No. & Year & Topic and Achievements & Objective Function & $\begin{array}{l}\text { Building Geometry Design } \\
\text { Variables }\end{array}$ & $\begin{array}{l}\text { (a) } \\
\text { (b) } \\
\text { (c) }\end{array}$ & $\begin{array}{l}\text { Algorithm } \\
\text { Simulation Engine } \\
\text { Framework/Method }\end{array}$ & Limitations \\
\hline [63] & 2002 & $\begin{array}{l}\text { Three studies about a multicriteria optimization of } \\
\text { building shape, internal wall partitions between } \\
\text { apartments, and heat source utilization in } \\
\text { multifamily housing }\left(2133.3 \mathrm{~m}^{2}\right) \text {. Decomposition in } \\
\text { part-problems: shape, internal partitions, heat } \\
\text { sources, and handling of global optimization } \\
\text { problem. The shape of the prismatic building was } \\
\text { determined in height, proportions of the sides, and } \\
\text { ORI. By replacing the rectangular form by a rectangle } \\
\text { and } 2 \text { trapezoids, an optimum shape was developed. }\end{array}$ & $\begin{array}{l}\text { - } \quad \text { Min. construction cost } \\
\text { - } \quad \text { Min. heating demand } \\
\text { sources }\end{array}$ & $\begin{array}{ll}\text { - } & \text { Wall length/area } \\
\text { Depth of space/building } \\
\text { wing } \\
\text { - } \quad \text { Height/Stacking } \\
\text { Angles of horizontal wall } \\
\text { inclination } \\
\text { - } \quad \text { GR, ORI, STR, TM, SHADE } \\
\text { HVAC/energy system }\end{array}$ & $\begin{array}{l}\text { (b) } \\
\text { (c) }\end{array}$ & $\begin{array}{l}\text { CAMOS } \\
\text { Analytic-numerical }\end{array}$ & $\begin{array}{l}\text { Very limited geometry } \\
\text { related design variables. }\end{array}$ \\
\hline [64] & 2002 & $\begin{array}{l}\text { Low-energy building energy optimization of a } \\
\text { community hall, } 1 \text { zone }\left(200 \mathrm{~m}^{2}\right) \text { based on combined } \\
\text { computer algorithm and human judgment. Finding } \\
\text { an extensive range of possible near-optimum designs. } \\
\text { Instead of the time-consuming process of classifying } \\
\text { the architectural appeal of each design case } \\
\text { generated by the GA (or to considerably reduce the } \\
\text { number of processed designs for time saving), a } \\
\text { histogram is proposed for each building variable. } \\
\text { Cases can be analyzed and worked up to } \\
\text { architectural sketches. Similar annual energy usage } \\
\text { performing models possess different designs. Models } \\
\text { with minimum heat losses apply insulation and } \\
\text { compact shape, while models with maximized solar } \\
\text { gains use more free form and greater windows. The } \\
\text { combination of the } 2 \text { strategies is problematic due to } \\
\text { summer overheating issues. }\end{array}$ & $\begin{array}{ll}\text { - } & \text { Min. annual energy } \\
& \text { consumption } \\
\text { - } & \text { Max. thermal losses } \\
\text { - } & \text { Max. thermal gains } \\
\text { - } & \text { Max. architectural appeal }\end{array}$ & $\begin{array}{ll}\text { - } & \text { Wall length/area } \\
& \text { Depth of space/building } \\
\text { - } & \text { wing } \\
& \text { Roof slope/eave/ridge } \\
\text { - } & \text { location } \\
\text { GR, ORI, STR, TM, SHADE }\end{array}$ & $\begin{array}{l}\text { (a) } \\
\text { (b) } \\
\text { (c) }\end{array}$ & $\begin{array}{l}\text { GA } \\
\text { Simplified dynamic } \\
\text { thermal model, } \\
\text { EXCALIBUR. } \\
\text { Custom calculation }\end{array}$ & $\begin{array}{l}\text { Very limited geometry } \\
\text { related design variables. } \\
\text { Conclusions about building } \\
\text { physics performance are not } \\
\text { new. GA; hence, only } \\
\text { near-optimal solutions. }\end{array}$ \\
\hline
\end{tabular}


Table 1. Cont.

\begin{tabular}{|c|c|c|c|c|c|c|c|}
\hline Ref. No. & Year & Topic and Achievements & Objective Function & $\begin{array}{l}\text { Building Geometry Design } \\
\text { Variables }\end{array}$ & $\begin{array}{l}\text { (a) } \\
\text { (b) } \\
\text { (c) }\end{array}$ & $\begin{array}{l}\text { Algorithm } \\
\text { Simulation Engine } \\
\text { Framework/Method }\end{array}$ & Limitations \\
\hline [65] & 2003 & $\begin{array}{l}\text { Multi-objective optimization of schematic rectangle } \\
\text { office and apartment building by composition of } \\
\text { walls, generation of shapes and define HVAC } \\
\text { systems. Pareto experiments: size and roof of each } \\
\text { room are modified by the GA. A large diversity of } \\
\text { the Pareto front building cases was achieved. } \\
\text { Optimal solution for heating is obtained in a single, } \\
\text { compact large building body with all-glazed S and W } \\
\text { facade. In lighting demand, the optimum case } \\
\text { provides small spaces easily penetrated by daylight } \\
\text { with S facing large glazed facades. }\end{array}$ & $\begin{array}{l}\text { - } \quad \text { Min. lighting demand } \\
\text { Min. heating thermal } \\
\text { energy demand } \\
\text { Min. construction } \\
\text { investment expenses }\end{array}$ & $\begin{array}{ll}\text { - } & \text { Geometry generation with } \\
\text { energy evaluation } \\
\text { - } & \text { Wall length/area } \\
\text { - } & \text { Depth of space/building } \\
\text { - } & \text { wing } \\
\text { Roof slope/eave/ridge } \\
\text { - } \quad \text { GRation } \\
\text { - } \quad \text { HVAC/ent, STR, TM, SHADE } \\
\end{array}$ & $\begin{array}{l}\text { (a) } \\
\text { (b) }\end{array}$ & $\begin{array}{l}\text { GA } \\
\text { DOE-2 }\end{array}$ & $\begin{array}{l}\text { No interdependencies and } \\
\text { energy related logic can be } \\
\text { detected in the random } \\
\text { generation of the building } \\
\text { form. Conclusions about } \\
\text { building physics } \\
\text { performance are not new. }\end{array}$ \\
\hline [66] & 2003 & $\begin{array}{l}\text { Office, } 1092 \mathrm{~m}^{2} \text {, decision support system (DSS), } \\
\text { involving two architects, two structural engineers, } \\
\text { and one building services engineer in evaluation. } \\
\text { Presenting a mathematical method. }\end{array}$ & $\begin{array}{ll}- & \text { Min. investment cost } \\
\text { - } & \text { Max. clear span } \\
& \text { Max. use of natural } \\
& \text { sources }\end{array}$ & $\begin{array}{ll}\text { - } & \text { Floor space } \\
& \text { Depth of space/building } \\
\text { - } & \text { Hing } \\
\text { - } & \text { Neight/stacking } \\
\text { - } & \text { Wall-floos floor ratio } \\
\text { - } & \text { Urban environment } \\
\text { - } & \text { GR, ORI, STR, TM, SHADE }\end{array}$ & $\begin{array}{l}\text { (a) } \\
\text { (c) }\end{array}$ & $\begin{array}{l}\text { GA } \\
\text { BGRID, Microsoft Visual } \\
\text { Basic }\end{array}$ & $\begin{array}{l}\text { Early stage optimization } \\
\text { framework, need further } \\
\text { development. Without } \\
\text { geometry generation (only } \\
\text { calculation). }\end{array}$ \\
\hline [68] & 2005 & $\begin{array}{l}\text { Proposing analytic target cascading (ATC), a } \\
\text { multidisciplinary hierarchical optimization method. } \\
\text { Presenting applicability via a pilot study } \\
\text { (office-workshop building } 597 \mathrm{~m}^{2} \text { ). Presenting and } \\
\text { proofing a mathematical method. }\end{array}$ & $\begin{array}{ll}\text { - } & \text { Max. area } \\
\text { - } & \text { Max. thermal comfort } \\
& \text { Min. cooling need } \\
& \text { Meed }\end{array}$ & $\begin{array}{ll}- & \text { Wall length/area } \\
- & \text { GR, ORI, STR, TM, SHADE } \\
\text { - } & \text { HVAC/energy system }\end{array}$ & $\begin{array}{l}\text { (b) } \\
\text { (c) }\end{array}$ & $\begin{array}{l}\text { EnergyPlus } \\
\text { Custom calculation, } \\
\text { superEGO, sequential } \\
\text { quadratic programming } \\
\text { (SQP) }\end{array}$ & $\begin{array}{l}\text { Early-stage optimization } \\
\text { framework, need further } \\
\text { development. }\end{array}$ \\
\hline
\end{tabular}


Table 1. Cont.

\begin{tabular}{|c|c|c|c|c|c|c|c|}
\hline Ref. No. & Year & Topic and Achievements & Objective Function & $\begin{array}{l}\text { Building Geometry Design } \\
\text { Variables }\end{array}$ & $\begin{array}{l}\text { (a) } \\
\text { (b) } \\
\text { (c) }\end{array}$ & $\begin{array}{l}\text { Algorithm } \\
\text { Simulation Engine } \\
\text { Framework/Method }\end{array}$ & Limitations \\
\hline [69] & 2005 & $\begin{array}{l}\text { The proposed method allows the designer to explore } \\
\text { and visualize design evolution, form generation, and } \\
\text { to interact in the optimization process. Through a } \\
\text { GUI, the user selects an example from the shapes, } \\
\text { and thereafter, the GA continues to search for the } \\
\text { best solution. Automated mesh and CFD } \\
\text { calculations. Example (generic, simple 1-room) for a } \\
\text { continuous evolution of optimization by } \\
\text { automatically creating discrete design instances and } \\
\text { morphing them in between the process. Compared to } \\
\text { conventional design: saving significant computation } \\
\text { time, possibility to track relationship between } \\
\text { variables and performances, possibility to evaluate } \\
\text { trade-off between diverse solutions, possible novel } \\
\text { design solution-configurations, because it is not } \\
\text { biased by the designer's view. }\end{array}$ & $\begin{array}{ll}\text { - } & \text { Max. thermal comfort } \\
\text { Max. ventilation } \\
\text { - } & \text { Min. temperforature } \\
\text { differences from target } \\
\text { - } & \text { Min. airflow velocity } \\
\text { differences from target }\end{array}$ & $\begin{array}{ll}\text { - } & \text { Wall length/area } \\
& \text { Depth of space/building } \\
\text { - } & \text { wing } \\
\text { - } & \text { Geight, ORI, STR, TM, SHADE } \\
\text { - HVAC/energy system }\end{array}$ & $\begin{array}{l}\text { (a) } \\
\text { (b) } \\
\text { (c) }\end{array}$ & $\begin{array}{l}\text { GA } \\
\text { Gambit, Ansys Fluent } \\
\text { (CFD) } \\
\text { GALib, C++, Java API }\end{array}$ & $\begin{array}{l}\text { GA; hence, only } \\
\text { near-optimal solutions. } \\
\text { Taking designer's } \\
\text { preferences into } \\
\text { consideration in the process } \\
\text { means that the selected } \\
\text { morph can be a promising } \\
\text { solution but may still not be } \\
\text { the guaranteed optimum. }\end{array}$ \\
\hline [70] & 2007 & $\begin{array}{l}\text { Optimization of the form of an office building on an } \\
\text { oval base. Presenting and proofing a mathematical } \\
\text { variational method. Heat losses and gains are } \\
\text { reduced by approx. } 10 \% \text {. Optimized oval form } \\
\text { performs better than circular or square base. }\end{array}$ & $\begin{array}{l}\text { - } \quad \text { Min. building cost } \\
\text { Min. heating cost (1-100 } \\
\text { years) }\end{array}$ & - $\quad$ Length of layout curves & (c) & $\begin{array}{l}\text { Variational method; } \\
\text { custom calculation }\end{array}$ & $\begin{array}{l}\text { Simple geometry, very } \\
\text { limited geometry-related } \\
\text { variables. }\end{array}$ \\
\hline [71] & 2009 & $\begin{array}{l}\text { Presentation of an MDO by breaking down the } \\
\text { system into building components (decomposition) } \\
\text { using CAD and IFC-codes. Interactive method } \\
\text { involving designer for quantitative and qualitative } \\
\text { analysis. Presenting and proofing a mathematical } \\
\text { method. Optimization of steel and wood frame load } \\
\text { bearing structures in an industry hall }\left(1200 \mathrm{~m}^{2}\right) \text {. }\end{array}$ & $\begin{array}{l}\text { Trade-off between } \\
\text { economic and } \\
\text { environmental user } \\
\text { preferences }\end{array}$ & $\begin{array}{ll}\text { - } & \text { Load-bearing structure } \\
\text { - GR, ORI, STR, TM, SHADE }\end{array}$ & $\begin{array}{l}\text { (a) } \\
\text { (c) }\end{array}$ & $\begin{array}{l}\text { MOGA } \\
\text { N-Square diagram } \\
\text { (design structure matrix), } \\
\text { ModelCenter }\end{array}$ & $\begin{array}{l}\text { Limited to variables of the } \\
\text { structure's geometry. }\end{array}$ \\
\hline [72] & 2009 & $\begin{array}{l}\text { MDO of a classroom building. Customized factorial } \\
\text { design (DOE). Test application of the PIDO software } \\
\text { to an AEC task. Investment cost of the structure } \\
\text { decreases as the length of the space increases, } \\
\text { because beam span reduces and becomes cheaper. } \\
\text { Operation cost increases as the length increases due } \\
\text { to greater surface area (heat loss), greater WWR with } \\
\text { more solar gains and cooling demand. }\end{array}$ & $\begin{array}{l}\text { Min. investment expenses } \\
\text { of the steel frame load } \\
\text { bearing structure } \\
\text { Min. LCC. of the steel } \\
\text { frame load bearing } \\
\text { structure }\end{array}$ & $\begin{array}{ll}\text { - } & \text { Wall length/area } \\
\text { - GR, ORI, STR, TM, SHADE }\end{array}$ & $\begin{array}{l}\text { (a) } \\
\text { (b) } \\
\text { (c) }\end{array}$ & $\begin{array}{l}\text { GA, gradient-based } \\
\text { algorithm } \\
\text { EnergyPlus, process } \\
\text { integration and design } \\
\text { optimization (PIDO). } \\
\text { ModelCenter, C++, } \\
\text { DesignExplorer, Darwin }\end{array}$ & $\begin{array}{l}\text { Conclusions about building } \\
\text { physics performance are not } \\
\text { new. GA; hence, only } \\
\text { near-optimal solutions. }\end{array}$ \\
\hline
\end{tabular}


Table 1. Cont.

\begin{tabular}{|c|c|c|c|c|c|c|c|}
\hline Ref. No. & Year & Topic and Achievements & Objective Function & $\begin{array}{l}\text { Building Geometry Design } \\
\text { Variables }\end{array}$ & $\begin{array}{l}\text { (a) } \\
\text { (b) } \\
\text { (c) }\end{array}$ & $\begin{array}{l}\text { Algorithm } \\
\text { Simulation Engine } \\
\text { Framework/Method }\end{array}$ & Limitations \\
\hline [73] & 2013 & $\begin{array}{l}\text { Residential house, economic incentives of energy } \\
\text { cost optimal curves in net zero energy home (NZEH). } \\
\text { MO analysis to find Pareto curves for the objective } \\
\text { function. Net-zero energy performance is possible } \\
\text { using passive solar design, improved HVAC system } \\
\text { efficiency, and renewable sources (PV-panels). The } \\
\text { cost-optimal case has an energy performance of } \\
\text { approx. 10,000 kWh/a. A NZEH costs approx. the } \\
\text { same as the reference building (Building America } \\
\text { reference building DOE 2010) over a 30-year } \\
\text { life-cycle. }\end{array}$ & $\begin{array}{ll}\text { - } & \text { Min. net-energy } \\
\text { consumption } \\
\text { - } \quad \text { Min. LCC }\end{array}$ & $\begin{array}{ll}\text { - } & \text { Aspect ratio } \\
\text { - } & \text { Roof slope/eave/ridge } \\
\text { - } & \text { location } \\
\text { GR, ORI, STR, TM, SHADE }\end{array}$ & $\begin{array}{l}\text { (a) } \\
\text { (b) }\end{array}$ & $\begin{array}{l}\text { Multi-objective algorithm } \\
\text { EnergyPlus, BEOpt }\end{array}$ & $\begin{array}{l}\text { In terms of building physics, } \\
\text { the conclusion is not new } \\
\text { knowledge. No information } \\
\text { is available about the } \\
\text { building geometry, size, etc. }\end{array}$ \\
\hline [74] & 2014 & $\begin{array}{l}\text { Multi-objective optimization of low-cost residential } \\
\text { housing (LCH) in } 3 \text { different climates (China). } \\
\text { Exemplary demonstration of the method. Geometry } \\
\text { related conclusions as design aid: In tropical } \\
\text { monsoon climates, in buildings with NV and/or AC } \\
\text { E-W, elongated rectangular shape is recommended. } \\
\text { In sub-tropics, the square shape is recommended } \\
\text { when NV is operated. Climate has a decisive impact } \\
\text { on building operation (passive or active) type. }\end{array}$ & $\begin{array}{ll}\text { - } & \text { Min. construction cost } \\
\text { - } & \text { Min. LCC } \\
& \text { Max. thermal comfort }\end{array}$ & $\begin{array}{ll}- & \text { Aspect ratio } \\
\text { - } & \text { Wall length/area } \\
& \text { Depth of space/building } \\
& \text { wing } \\
\text { - } & \text { GR, ORI, STR, TM, SHADE } \\
& \text { HVAC/energy system }\end{array}$ & $\begin{array}{l}\text { (a) } \\
\text { (b) } \\
\text { (c) }\end{array}$ & $\begin{array}{l}\text { Hybrid: PSO + } \\
\text { Hooke-Jeeves } \\
\text { EnergyPlus } \\
\text { GenOpt }\end{array}$ & $\begin{array}{l}\text { Very limited geometry } \\
\text { related design variables. }\end{array}$ \\
\hline [75] & 2015 & $\begin{array}{l}\text { Office, } 1 \text { representative floor }\left(1000-2000 \mathrm{~m}^{2}\right) \text {. } \\
\text { Searching for the set of design variables to minimize } \\
\text { heating and cooling load. DOE produced possible } \\
\text { design variable configurations. The design variables } \\
\text { were obtained statistically in a polynomial equation } \\
\text { form to determine the Pareto front. The method uses } \\
\text { a subset of all possible combinations of design } \\
\text { variables to ease exhaustive full factorial design with } \\
\text { a large number of test runs. (1) A large number of } \\
\text { variables are modeled and assessed as a screening to } \\
\text { find the important ones. (2) Functional relations are } \\
\text { explored about the variables' impact on objective } \\
\text { functions. (3) Optimization of the variables. } \\
\text { Variables of windows and air leakage affect energy } \\
\text { load significantly, while aspect ratio is ineffective. } \\
\text { HVAC system affect passive design. }\end{array}$ & $\begin{array}{l}-\quad \text { Min. heating load } \\
-\quad \text { Min. cooling load }\end{array}$ & $\begin{array}{ll}- & \text { Floor space } \\
\bullet & \text { Aspect ratio } \\
\text { - } & \text { GR, ORI, STR, TM, SHADE } \\
& \text { HVAC/energy system }\end{array}$ & $\begin{array}{l}\text { (a) } \\
\text { (b) }\end{array}$ & $\begin{array}{l}\text { NSGA-2, DOE } \\
\text { TRNSYS, R, } \\
\text { NIST/SEMATECH }\end{array}$ & $\begin{array}{l}\text { Very limited } \\
\text { geometry-related design } \\
\text { variables. Shape design } \\
\text { variables and enveloped } \\
\text { design variables (WWR, } \\
\text { materials) are } \\
\text { simultaneously examined; } \\
\text { hence, importance of } \\
\text { geometry as primary } \\
\text { architectural-functional } \\
\text { premise is overwritten by } \\
\text { design technologically } \\
\text { subsequent and more } \\
\text { expensive design steps. } \\
\text { Conclusions do not contain } \\
\text { new knowledge. }\end{array}$ \\
\hline
\end{tabular}


Table 1. Cont.

\begin{tabular}{|c|c|c|c|c|c|c|c|}
\hline Ref. No. & Year & Topic and Achievements & Objective Function & $\begin{array}{l}\text { Building Geometry Design } \\
\text { Variables }\end{array}$ & $\begin{array}{l}\text { (a) } \\
\text { (b) } \\
\text { (c) }\end{array}$ & $\begin{array}{l}\text { Algorithm } \\
\text { Simulation Engine } \\
\text { Framework/Method }\end{array}$ & Limitations \\
\hline [76] & 2015 & $\begin{array}{l}\text { MO optimization of thermal comfort and energy in } \\
\text { building design (multi-family house). GA optimizes } \\
\text { the back propagation (BP) ANN's weight and } \\
\text { threshold. Simulation-based GA-BP network training } \\
\text { and result validation. Thereafter, NSGA-II } \\
\text { optimization: evaluation of the potential solutions. } \\
\text { Significant (approx. 50\%) improvement in energy } \\
\text { and insignificant improvement in comfort. }\end{array}$ & $\begin{array}{l}\text { - Min. annual energy } \\
\text { consumption } \\
\text { - } \quad \text { Max. thermal comfort }\end{array}$ & $\begin{array}{ll}- & \text { SF } \\
\text { - } & \text { GR, ORI, STR, TM, SHADE }\end{array}$ & $\begin{array}{l}\text { (a) } \\
\text { (b) } \\
\text { (c) }\end{array}$ & $\begin{array}{l}\text { NSGA-II. GA-back } \\
\text { propagation network } \\
\text { (GA-BP) } \\
\text { EnergyPlus } \\
\text { Matlab }\end{array}$ & $\begin{array}{l}\text { Very limited } \\
\text { geometry-related design } \\
\text { variables. Limited to a } \\
\text { rectangular shape with a } \\
\text { known total floor area. } \\
\text { There is need for extensive } \\
\text { testing results for further } \\
\text { building geometry and type } \\
\text { training samples. }\end{array}$ \\
\hline [77] & 2019 & $\begin{array}{l}\text { MO BEO. Pareto optimization of geometry, envelope, } \\
\text { and energy systems. Proposed optimization } \\
\text { framework 'Harlequin' (unevenness in the diversely } \\
\text { oriented facades, materials, colors, WWR, } \\
\text { thermal-radiative characteristics): (1) GA generates } \\
\text { optimal non dominated solutions; (2) Smart } \\
\text { exhaustive sampling of optimal (minimized) PEC, } \\
\text { global cost (GC) and investment cost (IC) scenarios. } \\
\text { Decision makers can choose the "best" solution } \\
\text { according to their needs. Example (office, } 2700 \mathrm{~m}^{2} \text { ) } \\
\text { modelling and calculations. Recommendations on } \\
\text { optimal geometry (aspect ratio 1) and WWR. }\end{array}$ & $\begin{array}{l}\text { - Min. heating energy } \\
\text { demand } \\
\text { Min. cooling energy } \\
\text { demand } \\
\text { - Min. lighting energy } \\
\text { demand } \\
\text { - Min. thermal discomfort } \\
\text { hours }\end{array}$ & $\begin{array}{ll}- & \text { Aspect ratio } \\
- & \text { GR, ORI, STR, TM, SHADE } \\
& \text { HVAC/energy system }\end{array}$ & $\begin{array}{l}\text { (a) } \\
\text { (b) } \\
\text { (c) }\end{array}$ & $\begin{array}{l}\text { MOGA } \\
\text { EnergyPlus } \\
\text { MATLAB }\end{array}$ & $\begin{array}{l}\text { Very limited } \\
\text { geometry-related design } \\
\text { variables. GA; hence, only } \\
\text { near-optimal solutions, 'ad } \\
\text { hoc' randomly solution } \\
\text { generation. Conclusions } \\
\text { about building physics } \\
\text { performance are not new. } \\
\text { The method is not } \\
\text { user-friendly and requires } \\
\text { expertise in programming } \\
\text { and BEO. Definition of } \\
\text { generation and population } \\
\text { sizes are not justified. }\end{array}$ \\
\hline
\end{tabular}


Table 1. Cont.

\section{Ref. No. \\ Year \\ Topic and Achievement}

$\mathrm{SO}$ and $\mathrm{MO}$ environmental optimization of

apartment buildings $\left(740 \mathrm{~m}^{2}\right)$. Presented method

with LCEI example calculations. Approx. 4-6 story

compact, close-to-cube shape with somewhat larger S

facade, large WWR (approx. 60\%) to the S and small

WWR to the N. In optimization of the trade-off

between embodied and operational impact, the

single objective optimization (SO) preferred compact

shape with fully glazed facades and the operational

impact optimization resulted in large southern

facade (max. solar gains) and extensive insulation

(loss reduction). In the case of the optimization of SO

+ MO: a nearly cubic shape with optimized WWR fo

solar gains (double glazing) in the S facade and the

rest of the facades are optimized for low

transmission losses (triple glazing). 60-80\%

environmental savings achieved in $\mathrm{MO}$

environmental impact optimization. Similar results

are achieved with significantly diverse solutions.

- Min. LCEI (50 years, EN 15978)

- Min. operational and

Min. embodied impact

based on non-renewable

cumulative energy

demand (CED).
Building Geometry Design

Variables (a) Algorithm

(b) Simulation Engine

(c) Framework/Metho

\section{Limitations}

$\bullet$

GR, ORI, STR, TM, SHADE

HVAC/energy system (a) GA GH, Ladybug, Honeybee
Octopus, Steady-state model EN ISO 13790
GA: hence, only a range of near-optimal solutions. GA cts as a 'black box'; hence, the designer cannot follow what is exactly happening in the calculations. Only steady-state energy calculations.
MO optimization of a regular classroom space. ANN $\quad$ • Min. air-conditioning a popular type of arrogate moders regular simulation time by factor approx. 2570 $14.2-24.6 \%$ average performance improvement in the 3 objective function (integrated solution).
Min. lighting energy consumption

- Max. average UDI
- Min. hours of thermal
- Wall length/area

- Depth of space/building wing

- Height/stacking

- GR, ORI, STR, TM, SHADE (a) NSGA-II

(b) EnergyPlus, Radience

(c) GH, Python, Ladybug, Colibri, Geatpy
Very limited

geometry-related design variables. Randomly generated design cases by parametric tools for ANN training dataset; hence, the optimum may be missed. Optimum may be missed. Unclear distinctions in
different cases using different cases using alternating geometry, solar absorptance.

Conclusions about building physics performance are not new. 
Table 1. Cont.

\begin{tabular}{|c|c|c|c|c|c|c|c|}
\hline Ref. No. & Year & Topic and Achievements & Objective Function & $\begin{array}{l}\text { Building Geometry Design } \\
\text { Variables }\end{array}$ & $\begin{array}{l}\text { (a) } \\
\text { (b) } \\
\text { (c) }\end{array}$ & $\begin{array}{l}\text { Algorithm } \\
\text { Simulation Engine } \\
\text { Framework/Method }\end{array}$ & Limitations \\
\hline [80] & 2021 & $\begin{array}{l}\text { Machine learning-based thermal optimization of } \\
\text { residential buildings (2000; } 4000 ; 6000 \mathrm{~m}^{2} \text { ). Latin } \\
\text { Hypercube sampling (LHS) generates building } \\
\text { configurations. Gradient boosting machine (GBM) is } \\
\text { trained by simulation-based dataset for target result } \\
\text { prediction. GA optimizes with the surrogate GBM } \\
\text { model. Optimal aspect ratio values were found in the } \\
3 \text { alternating locations (climates) and } 3 \text { different } \\
\text { building heights }(5,10 \text { and } 15 \text { ) ranging } 0.67-1.67 \text {. }\end{array}$ & $\begin{array}{l}\text { - } \quad \text { Min. heating load } \\
\text { Min. cooling load under } \\
\text { investment cost } \\
\text { constraints. }\end{array}$ & $\begin{array}{ll}- & \text { Aspect ratio } \\
- & \text { Height/stacking } \\
\text { - } & \text { GR, ORI, STR, TM, SHADE }\end{array}$ & $\begin{array}{l}\text { (a) } \\
\text { (b) } \\
\text { (c) }\end{array}$ & $\begin{array}{l}\text { GA } \\
\text { EnergyPlus, DEAP } \\
\text { Gradient boosting } \\
\text { machine (GBM) }\end{array}$ & $\begin{array}{l}\text { Very limited geometry } \\
\text { related design variables. } \\
\text { GA; hence, only } \\
\text { near-optimal solutions, } \\
\text { randomly generated. } \\
\text { Conclusions about building } \\
\text { physics performance are not } \\
\text { new. Definition of } \\
\text { generation and population } \\
\text { sizes are not justified. }\end{array}$ \\
\hline [81] & 2021 & $\begin{array}{l}\text { The position and the height of residential high-rise } \\
\text { buildings has a significant effect on internal and } \\
\text { external (urban spaces) visual and thermal comfort. } \\
\text { Top } 10 \text { optimized cases (urban configurations) were } \\
\text { selected. }\end{array}$ & $\begin{array}{ll}\bullet & \text { Max. DF } \\
- & \text { Max. sky view ratio } \\
- & \text { Max. window sunlight } \\
& \text { hours } \\
\bullet \quad & \text { Max. site sunlight hours } \\
-\quad & \text { Max. universal thermal } \\
& \text { climate index }\end{array}$ & $\begin{array}{ll}\text { - } & \text { Height/stacking } \\
& \text { Urban environment }\end{array}$ & $\begin{array}{l}\text { (a) } \\
\text { (b) } \\
\text { (c) }\end{array}$ & $\begin{array}{l}\text { NSGA-II } \\
\text { Radiance, Daysim } \\
\text { Matlab, Grasshopper, } \\
\text { Ladybug }\end{array}$ & $\begin{array}{l}\text { Limited geometry } \\
\text { optimization. Mainly visual } \\
\text { comfort optimization only. }\end{array}$ \\
\hline
\end{tabular}


Besides the main building envelope design variable (BEDV) features (e.g., structure and material thermal properties, WWR, shading and orientation), aspect ratio, the ratio of the two axes of a rectangular office building [67], appears as a form-related design variable in the optimization procedure to minimize LCA and lifecycle environmental impact (LCEI). The aspect ratio 1 was preferred for cost reduction, but a rectangular shape with a long southern side performed better in energy efficiency. However, the considerations of BGDV is limited to one value of the layout of a simple single-story cuboid block. In another limited study, a single design variable was examined, and the results did not show any evidence of a new methodology. A reduction in energy consumption by over $15 \%$ is possible in many instances, compared to a building of a less efficient aspect ratio, such as 4.2:1 (x:y). Philip McKeen and Alan S. Fung examined the energy consumption of varying aspect ratio in multi-unit residential buildings in Canadian cities to identify energy-efficient designs across Canada [83].

Another study of an oval-shaped office building [70] aimed to achieve minimum construction costs and heating demand by manipulating the layout between circular and oval shapes. Here, the heat losses and gains were only reduced by approximately $10 \%$, while the measure of shape modification takes place in a minimum range, making it impractical even for early-stage design. In [66], collaboration between practicing designers was integrated in the optimization of a simple office building with constraints of rectangular shape, number of stories, and dimensions of layout (wall-floor ratio, depth of space), and location of cores and atria to create large clear spans, minimize cost, and maximize daylight and natural ventilation. Architects and structural engineers were consulted regarding the objective functions; however, limitations of the variables and evaluations and the absence of energy simulations require further development. According to Philipp Geyer [71], a designer can interact with the automated optimization process of an industry hall by breaking down the architectural design into different optimization models. Economic, environmental, and user preference objectives were set by combining the load bearing structure (a steel and wood framework) of a hall. The detailed load-bearing structure optimization delivers innovative results, though the space geometry remains here almost untouched. The authors of [68] propose hierarchical optimization of a small, simple cuboid workshop and office building, seeking for optimum wall sizes, WWR, heating-cooling setpoints, and mean air velocity to calculate optimum overall performance of thermal comfort and energy load.

An optimization method is proposed in [67], with MOGA for the early design stage, demonstrated through an example office of $1000 \mathrm{~m}^{2}$. LCEI could be reduced by $65 \%$, and the operation within LCEI decreased by 20\%. Aspect ratio 1 was preferred for cost reduction, but the rectangular shape with a long side to the south performed better in energy efficiency. The trade-off between optimum aspect ratio for environment or for cost efficiency aspects is defined; nevertheless, the paper dealt only with simple geometries and variables and instead focused on presenting and proofing a mathematical method. Active system variables are often manipulated together with the previously mentioned main BEDV-s (e.g., WWR and window positions) and some typical BGDV-s; aspect ratio, number of floors, roof slope, size and area of the space $[61,64,73,75,76]$, or the length and height of one wall of the simple box-shaped building or single-room $[63,72,74,79]$. These variables are commonly used because they are easy to quantify for the algorithms.

Searching the set of design variables to minimize heating and cooling load, a study [75] obtained design variables statistically in a polynomial equation form to determine of the Pareto front. This method used a subset of all possible combinations of design variables to calculate the full factorial design. The variables of windows and air leakage affected energy load significantly, while aspect ratio turned out to be ineffective. Furthermore, the HVAC system affected the passive design with very limited geometry related design variables. The study did not deliver any new conclusions. Shape design variables and envelope design variables (WWR, materials) are simultaneously examined; hence, the 
significance of geometry as a primary architectural-functional premise is overwritten by design-technological premises and more expensive design steps.

Energy savings up to 50\% are achieved in a multi-family house in [76], whereas the objectives of thermal and visual comfort and energy consumption could be improved by $14.2-24.6 \%$ in [79]. By replacing the rectangular form by a rectangle and two trapezoids, an optimum shape was developed in [63] for a residential building. An elongated rectangular shape with E-W axis is recommended in tropical monsoon climates when natural ventilation $(\mathrm{NV})$ or air-conditioning (AC) is operated [74]. In sub-tropics, the square shape is preferable when ventilated naturally. The width and height of the external walls of four building zones orientated according to the cardinal points were manipulated along with different tilted roof variations to develop an optimized trade-off between heating and lighting load in [65]. The best building geometries and WWR options for heating and the best solutions for lighting demand are gained in a process, where no interdependencies and energy-related logic can be detected in the random generation (genetic algorithm GA) of the form, since the discussion of the study focusses mainly on the algorithm as a technique [84]. Novel ideas relating to the building physics remain lacking.

Calculated by CFD, another project [69] optimizes the length, width, and height, window, air in- and outlet dimensions, and positions of a box-shaped space to perform as close as possible solutions to the specified air temperature and velocity goals. Using a graphical user interface (GUI), the user is able to interact in the process and study the thermal and fluid-flow performance of selected examples within the complete design space and review trade-offs for different scenarios. The user chooses a point of interest, and the algorithm looks for the optimum solutions around it. However, only a few small geometry variations are considered, whereas factors regarding the shape of the space remain practically untouched. An interactive optimization tool (AMCE) [62] is presented, which takes into account building area, height, number of levels, roof form, and aspect ratio for the sketch plan process including client, design team, and public authority interventions. The study is limited to the introduction of the method and the software without examples of application.

B. Kiss and Z. Szalay conducted single-objective optimization (SOO) in six LCA environmental indices [78], operational and embodied impacts, as well as multi-objective optimization (MOO) considering all LCA simultaneously or both operational and embodied impacts together. The SOO resulted in a relatively compact shape with fully glazed facades; the operational impact optimization resulted in a large southern facade (for improved solar gain) and extensive insulation (to reduce energy transfer). By combining SOO and MOO, a nearly cubic shape with a WWR southern facade optimized for solar gain (double glazing) was reached with the rest of the facades aiming for low transmission losses (with triple glazing). Thus, 60-80\% environmental savings were achieved in the Pareto optimum models in the environmental impact MOO. Nevertheless, spatial parameters are restricted here to aspect ratio and number of floors, since more emphasis was put on the trade-off between the LCA impact of variables related to embodied material and the operation of HVAC systems. Using another approach [85], the building geometry and renewable energy utilization are first optimized and adopted as the basis of the building model. In the second stage, the trade-off between embodied and operational energy with alternative façades was evaluated. In this way, optimal building designs can be ensured, which do not just rely on operational energy.

Fabrizio Ascione et al. [77] propose a comprehensive optimization framework called "Harlequin" by finding optimal aspect ratios among 1-8 in three climatic locations and various building heights (5-, 10-, and 15-level). A compact aspect ratio of 1 was preferred. In [50], the authors made an attempt to optimize the objectives of useful daylight illuminance (UDI) and energy use intensity (EUI) in a rectangular building with a classic pitched roof, giving a few recommendations about the application of BGDV-s, as building depth (greatly influenced by the climate) and roof ridge location in three different climate zones. Based on the results, the inductive building physics insights do not provide new relevance. 
Sadik Yigit established a gradient boosting machine learning (GBM)-based hybrid GA optimization system that looked for optimal residential building block solutions with low investment budgets and high energy efficiency by combining variables of floor numbers, area, aspect ratio, orientation, and envelope thermal properties and WWR in the three most crowded cities in Turkey [80]. Optimal aspect ratio values were found in the three alternating locations (climates) and three various building heights (5, 10, and 15 stories) ranging from $0.67-1.67$, but the main focus is rather on the validation of the method rather than on geometry related optimization. However, geometry-related design variables were very limited and the conclusions about building physics performance are not new. A GA ensured only near-optimal solutions due to randomly generated data, and the definition of the population sizes are not justified.

Further research conducted geometry-related performance optimization using an automatic recognition and conversion method with a designer preference-based optimization algorithm to help designers in the decision-making process [82]. The algorithm proposes optimal building model versions to the designer, who should select the preferred one. The algorithm requires a concrete, initial design case for further modifications, and in this way, the results are limited to a specific case with only a few shapes.

In urban design, the position and the height of residential high rise buildings has a significant effect on the internal (buildings) and external (urban spaces) comfort indices: DF, sky view ratio, window sunlight hours, site sunlight hours, and universal thermal climate index indicators were examined in a MOO study [81] by the modification of the building blocks' layout.

\subsection{Building Geometry Variables to Elaborate the Level of Complexity}

Additional emphasis on geometry modification is provided by further BECEDO research activities (Table 2). A unique method is introduced in [38] to modify building shape by manipulating the corner points of the geometry in an 'agent-child' point coordinate-system. With the objective function of minimizing energy flow on the surfaces, a cuboid building body was formed and optimized to a limited number of abstract forms without windows or any additional building structures or systems. Reduction in energy consumption was evaluated to find the optimal abstract geometries, while creating impractical, formal results (with complicated surfaces) and neglecting that these forms require higher construction and material expenses, combined with higher LCA impact. A pentagon-shaped office layout was optimized to minimize LCC and LCEI by varying WWR, structures' materials, and shading as well as the dimensions of the layout and interconnecting angles [45]. Low LCC is performed by close to regular pentagon layout-forms, and low LCEI is caused by wider south-facing shapes, which demonstrates that geometry is integral to the relationship between balancing energy efficiency with investment costs. However, the study primarily focuses on demonstrating the method with a simple example. Shape grammar is used for the formal structure generation of patio houses in the urban context [86] as well as for office building conversion into housing by deriving layouts according to translated mathematical grammar-shape rules [87]. Although these two previous studies offer the potential for energy optimization, they only address the generation of layout designs. 
Table 2. BECEDO research using advanced building shape design variables.

\begin{tabular}{|c|c|c|c|c|c|c|c|}
\hline Ref. No. & Year & Topic and Achievements & Objective Function & $\begin{array}{l}\text { Building Geometry Design } \\
\text { Variables }\end{array}$ & $\begin{array}{l}\text { (a) } \\
\text { (b) } \\
\text { (c) }\end{array}$ & $\begin{array}{l}\text { Algorithm } \\
\text { Simulation Engine } \\
\text { Framework/Method }\end{array}$ & Limitations \\
\hline [38] & 2009 & $\begin{array}{l}\text { Proposing an agent-based geometry generation } \\
\text { system based on hierarchical geometry relations. } \\
\text { Morphing geometries through agent and child } \\
\text { points as 3D corner points of geometries. A } \\
\text { cuboid reference building geometry ( } 225 \mathrm{~m}^{2} \\
\text { redisential building) was modified to an optimal } \\
\text { shape with minimal heat loss. Unique geometry } \\
\text { generation approach (free forming) to handle } \\
\text { complete building geometries in free form. } 12 \% \\
\text { heat load by volume and } 6 \% \text { heat flow per } \\
\text { envelope area could be saved. }\end{array}$ & $\begin{array}{l}\text { Min. heat exchange } \\
\text { through the envelope }\end{array}$ & $\begin{array}{ll}\text { - } & \text { Corner points of 3D } \\
\text { - } & \text { geometries } \\
& \text { Grid position of each room }\end{array}$ & $\begin{array}{l}\text { (a) } \\
\text { (b) } \\
\text { (c) }\end{array}$ & $\begin{array}{l}\text { GA } \\
\text { EnergyPlus, } \\
\text { MATLAB, m-file }\end{array}$ & $\begin{array}{l}\text { Simple example of a building with } \\
\text { limited geometry variables and } \\
\text { impractical and building envelope } \\
\text { surfaces, making construction } \\
\text { expensive. }\end{array}$ \\
\hline [39] & 2020 & $\begin{array}{l}\text { Multi-objective building shape and envelope } \\
\text { optimization of an apartment block ( } 8000 \mathrm{~m}^{3} \text {, } \\
4-8 \text { levels; } 2673 \mathrm{~m}^{2}, 6 \text { levels). Phase I: geometry } \\
\text { optimization of common linear (I), L- (L), court } \\
\text { (O), C- (C), T- (T), H- (H), cross (X), and Y-shaped } \\
\text { (Y) buildings (LOD 100) with WWR and ORI } \\
\text { options. O, T, H, X, and Y-shapes perform as } \\
\text { Pareto optimal solutions. Main reason for that is } \\
\text { the self-shading effect of these bodies and the } \\
\text { minimization of the SF. The optimal building } \\
\text { geometry as output from Phase I is input to } \\
\text { Phase II, applying passive and active strategies } \\
\text { (LOD 300) to further optimization. }\end{array}$ & $\begin{array}{ll}- & \text { Min. heating demand } \\
- & \text { Min. cooling demand } \\
\text { - } & \text { Min. energy cost } \\
\text { - } & \text { Min. investment cost } \mathrm{CO}_{2} \text { emissions }\end{array}$ & $\begin{array}{ll}\text { - } & \text { Shape proportion (SP) } \\
\text { Geometry generation with } & \text { energy evaluation } \\
\text { - } & \text { GR, ORI, STR, TM, } \\
& \text { SHADE }\end{array}$ & $\begin{array}{l}\text { (a) } \\
\text { (b) } \\
\text { (c) }\end{array}$ & $\begin{array}{l}\text { Active-archive NSGA-II } \\
\text { EnergyPlus } \\
\text { Own developed } \\
\text { calculation platform }\end{array}$ & $\begin{array}{l}\text { Definition of generation and } \\
\text { population sizes is not justified (only } \\
\text { according to the literature). } \\
\text { Geometry optimization of useful } \\
\text { floor space and volume, but missing } \\
\text { consideration of the different } \\
\text { envelope sizes of the diverse shapes } \\
\text { and their investment cost. Only } \\
\text { single-zone thermal simulation } \\
\text { models of multi-story blocks are } \\
\text { calculated. This simplification leads } \\
\text { to inaccurate or unrealistic results. } \\
\text { GA; hence, only near-optimal } \\
\text { solutions, randomly generated and } \\
\text { therefore hypothesized conclusions. } \\
\text { Conclusions about building physics } \\
\text { performance are not new. }\end{array}$ \\
\hline
\end{tabular}


Table 2. Cont.

\begin{tabular}{|c|c|c|c|c|c|c|c|}
\hline Ref. No. & Year & Topic and Achievements & Objective Function & $\begin{array}{l}\text { Building Geometry Design } \\
\text { Variables }\end{array}$ & $\begin{array}{l}\text { (a) } \\
\text { (b) } \\
\text { (c) }\end{array}$ & $\begin{array}{l}\text { Algorithm } \\
\text { Simulation Engine } \\
\text { Framework/Method }\end{array}$ & Limitations \\
\hline [44] & 2010 & $\begin{array}{l}\text { MO optimization of solar energy use (heating, } \\
\text { lighting) in an urban district with } \\
18,000 \text { evaluations. 'Terraces Flat Roofs' (E-W } \\
\text { building axis), 'Slabs Sloped Roofs' (N-S } \\
\text { building axis) and 'Terrace Courts' (courtyards) } \\
\text { morphology versions were examined, and the } \\
\text { latter performed best in energy gains and losses } \\
\text { based on greatest collector surface while the } \\
\text { volume remain compact. Medieval settlement } \\
\text { morphology has more form-related (compact) } \\
\text { structure to minimize losses. Modern settlement } \\
\text { morphology requires new forms with less } \\
\text { density to utilize solar gain. }\end{array}$ & $\begin{array}{l}\text { Max. solar exposure } \\
\text { offset on envelope by } \\
\text { thermal losses in } \\
\text { heating season } \\
\text { Max. solar exposure } \\
\text { offset on } \\
\text { envelope-by-envelope } \\
\text { heat losses and min. } \\
\text { volume. }\end{array}$ & $\begin{array}{ll}\text { - } & \text { \% of permitted urban } \\
\text { morphology volume } \\
\text { - } & \text { ORI } \\
\text { - } & \text { Height/Stacking } \\
\text { Roof/Eave/Ridge } \\
\text { dimension, slope, location }\end{array}$ & $\begin{array}{l}\text { (a) } \\
\text { (b) } \\
\text { (c) }\end{array}$ & $\begin{array}{l}\text { EA } \\
\text { RADIANCE } \\
\text { MOO, OSMOSE, } \\
\text { cumulative sky model, } \\
\text { Matlab }\end{array}$ & $\begin{array}{l}\text { EA was used with Pareto } \\
\text { optimization to make up for the } \\
\text { missing convergence check. This } \\
\text { way, only a nearly optimal solution } \\
\text { is achievable. }\end{array}$ \\
\hline [45] & 2006 & $\begin{array}{l}\text { Pentagon-shaped office layout optimization. The } \\
\text { length-bearing method (polygon represented by } \\
\text { the bearing = angle between north and an edge, } \\
\text { ORI = 1st edge bearing) perform better than the } \\
\text { length-angle method (polygon represented by } \\
\text { length of the edges and the angle between two } \\
\text { adjacent edges, ORI = 1st edge angle to true } \\
\text { north) in the framework of MOGA. Low LCC is } \\
\text { performed by close to regular pentagons and low } \\
\text { LCEI is caused by larger (wider) south facing } \\
\text { facade-shapes. }\end{array}$ & $\begin{array}{ll}\text { - } & \text { Min. LCC } \\
\text { Min. LCEI }\end{array}$ & $\begin{array}{ll}\text { - } & \text { Angle of horizontal wall } \\
\text { inclination } \\
\text { - } \\
\text { Roof/Eave/Ridge } \\
\text { dimension, slope, location } \\
\text { - } \quad \text { GR, ORI, STR }\end{array}$ & $\begin{array}{l}\text { (a) } \\
\text { (b) }\end{array}$ & $\begin{array}{l}\text { MOGA } \\
\text { RS Means, ATHENA }\end{array}$ & $\begin{array}{l}\text { Demonstration of the method rathe } \\
\text { than comprehensive geometry } \\
\text { generation and optimization. GA; } \\
\text { hence, only near-optimum search. }\end{array}$ \\
\hline
\end{tabular}


Table 2. Cont.

\section{Ref. No. \\ Year \\ Topic and Achievements}

Optimization of simple office building block

geometry (energy demand) in an urban

environment coupled with renewable energy

potentials and concurrent decentralized

multi-energy systems (MES). Optimization of the

corner points horizontal and vertical positions.

In extreme carbon scenarios, the optimal forms

are regular, while in the in-between carbon

scenarios, the geometries become more irregular

[49] $2019 \quad$ (balancing solar and daylight harvesting with

available floor space and ORI). Consecutive

optimization: 1st geometry optimization, and

then energy system and solar potentia

optimization. Nested optimization: geometry,

energy, and solar optimization takes place

simultaneously. The consecutive optimal shapes

have N-S ORI, while the nested ones have

isotropic bodies. Shape and energy systems are

mutually dependent and should be

simultaneously optimized.

Different letter-shaped, rectangle, and trapezoid

layouts are investigated in 2-story residential

homes. Rectangle and trapezoid shapes have

best performance. When only shape variable is

considered: $\mathrm{S}$ facing trapezoid in sunny heating

climates, and $\mathrm{N}$ facing trapezoid in cooling

climates are preferable due to solar gain throug

windows. When geometry, WWR, and materia

variables are considered in combination: little

[88] 2010 difference occurs between the optimal shape

geometry and WWR in colder climate zones, and

in warmer climates, overheating inverts this

in war Architects have geat flexibility in

form design in cold climates. Results of building

shapes with max. LCC (max. surfaces, aspect

ratio) show large differentiations, indicating

building geometry's decisive impact on energy efficiency.
- Min. investment cost

Min. operational carbon emission
Geometry generation with evaluation

- Height/stacking

Coordinates of the layout corners (b) EnergyPlus

(c) RBFOpt (Radial Basis Function Optimization) (a) Algorithm

Black-box optimizer because

geometrical optimization problem is

difficult to solve in an analytical

form and simulation programs are

complex. Limited simplified

geometries. Since shape has a

decisive impact on energy demand

system efficiencies and renewable

energy potential, as well as HVAC

systems may rapidly become

obselete compared to a building

geometry and structure, certain

preliminary choices on energy

systems should not influence

building densities, ORI and shapes

or should be carefully considered

with LCA in mind. (b) Simulation Engine

(c) Framework/Method
- $\quad$ Min. LCC

- Depth of space/building

wing

HVAC/energy system
- GR, ORI, STR, TM,
This study did not consider that after optimization of the mass shape significant savings in further passive and active improvements are achievable: shape design

modifications have lower initial costs compared to subsequent investments into material and

HVAC systems (LCCA); hence,

building geometry is not

independent from energy design. (b) GA

(c) MATLAB, Perl 
Table 2. Cont.

\begin{tabular}{|c|c|c|c|c|c|c|c|}
\hline Ref. No. & Year & Topic and Achievements & Objective Function & $\begin{array}{l}\text { Building Geometry Design } \\
\text { Variables }\end{array}$ & $\begin{array}{l}\text { (a) } \\
\text { (b) } \\
\text { (c) }\end{array}$ & $\begin{array}{l}\text { Algorithm } \\
\text { Simulation Engine } \\
\text { Framework/Method }\end{array}$ & Limitations \\
\hline [89] & 2011 & $\begin{array}{l}\text { Different letter-shaped, rectangle, and trapezoid } \\
\text { layouts are investigated in 2-storey residential } \\
\text { buildings. SO optimization of the HVAC systems, } \\
\text { simultaneous (full) optimization of building } \\
\text { envelope and HVAC system and in a sequential } \\
\text { manner (1st envelop then HVAC optimization). } \\
\text { According to different optimization domains } \\
\text { (envelope and HVAC) and constraints diverse } \\
\text { shapes perform better. In five US cities, the full } \\
\text { optimization rectangle shape (AR 1) performs } \\
\text { best, while in energy cost full optimization, } \\
\text { diverse forms deliver the best results. }\end{array}$ & $\begin{array}{ll}-\quad & \text { Min. LCC (30 years) } \\
\text { - } & \text { Min. energy cost }\end{array}$ & $\begin{array}{ll}\text { - } & \text { Aspect ratio Depth of } \\
\text { space/building wing } \\
\text { - } \\
\text { GR, ORI, STR, TM, } \\
\text { SHADE } \\
\text { - } \quad \text { HVAC/energy system }\end{array}$ & $\begin{array}{l}\text { (a) } \\
\text { (b) }\end{array}$ & $\begin{array}{l}\text { Sequential search, PSO, } \\
\text { GA } \\
\text { DOE-2 }\end{array}$ & $\begin{array}{l}\text { No interdependencies between } \\
\text { BGDV and optimization results } \\
\text { provided. }\end{array}$ \\
\hline [90] & 2013 & $\begin{array}{l}\text { Geometry optimization of a tunnel formed } \\
\text { greenhouse }\left(1000 \mathrm{~m}^{3}\right) \text { and a } 25,000 \mathrm{~m}^{2} \text { spherical } \\
\text { city-hall inspired by the existing London } \\
\text { City-Hall (Arch.: Norman Foster): energy } \\
\text { savings roughly estimated. Axes ratio and arch } \\
\text { ratio of ellipsoid sphere geometry has greatest } \\
\text { effect on energy use, best axes ratio is } 1.0-1.2 \\
\text { (almost rotationally symmetric cupola } \\
\text { geometries). Orientation does not significantly } \\
\text { influence the results. }\end{array}$ & - $\quad$ Max. energy efficiency & $\begin{array}{ll}\text { - } & \text { Significant geometry } \\
& \text { modification } \\
\text { - } & \text { Ratio of sphere geometry } \\
\text { - } & \text { Depth of space/building } \\
& \text { wing } \\
\text { - } & \text { Height/Stacking } \\
\text { - } & \text { GR, ORI, STR, TM, } \\
& \text { SHADE }\end{array}$ & $\begin{array}{l}\text { (a) } \\
\text { (b) } \\
\text { (c) }\end{array}$ & $\begin{array}{l}\text { Parallel direct search } \\
\text { based on ES (GA) } \\
\text { Autodesk Ecotect } \\
\text { Modified differentiation } \\
\text { evolution method }\end{array}$ & $\begin{array}{l}\text { Limited geometry related variables } \\
\text { and poor description of calculations, } \\
\text { modelling, and results. }\end{array}$ \\
\hline [91] & 2010 & $\begin{array}{l}\text { Hybrid evolutionary algorithm is applied with } \\
\text { constraint handling as a method for urban } \\
\text { building configuration optimization. Three } \\
\text { applications: cuboid buildings in an urban block; } \\
\text { complex extension building roof shapes adjacent } \\
\text { to an existing house; rectangular plan building's } \\
\text { volume is parametrized by Fourier series. }\end{array}$ & - Max. solar energy use & $\begin{array}{ll}- & \text { Height/stacking } \\
\text { - } & \text { Roof geometry } \\
& \text { Volume }\end{array}$ & $\begin{array}{l}\text { (a) } \\
\text { (b) }\end{array}$ & $\begin{array}{l}\text { CMA-ES (covariance } \\
\text { matrix adaptation } \\
\text { evolution strategy), HDE } \\
\text { (hybrid differential } \\
\text { evolution). } \\
\text { RADIANCE }\end{array}$ & $\begin{array}{l}\text { Interesting, diverse applications of } \\
\text { the method, but demonstrative } \\
\text { rather than systematic optimal } \\
\text { building generation procedure. }\end{array}$ \\
\hline
\end{tabular}


Diversely shaped layouts are assessed in work [88] using trapezoid, rectangular, and letter-shapes $(\mathrm{T}, \mathrm{L}, \mathrm{U},+, \mathrm{H})$ of flat roofed detached houses in combination with several thermal features of the building envelope, HVAC system variables, and operation setpoints to compare energy and LCC performance. The form of the mass had a large impact on energy performance, while after the optimization of all variables, the effect of varying shapes on the LCC was overwritten, allowing designers more freedom to select different forms. Surprisingly, this study focused on the configuration of all design variants simultaneously and did not take into consideration that, after previous optimization of the mass shape, significant savings in subsequent passive and active improvements are achievable. This consecutive optimization process (firstly, shape; secondly, the remaining passive variables; and thirdly, the active measures) is proved to be effective in other literature [39].

Moncef Krarti et al. [89] incorporated the same building shapes in an envelope and HVAC system optimization as in research [88]. SO optimization of the HVAC systems, simultaneous (full) optimization of the building envelope and HVAC system and in a sequential manner (1. envelop, 2. HVAC optimization) energy cost vs. LCC were carried out. With numerous optimization domains, different shapes evolved as the best performing versions. In five US cities, full optimization of the rectangle shape (AR 1) performs best, but when prioritizing energy cost optimization, more diverse forms produce the best results. Regrettably, the cause and effect interdependencies between shapes and results remained unclear, and the focus is primarily on the objective functions and on the methodology. Adriana Ciardiello et al. proposed eight shapes with four shape proportions each to reach the optimal objective function of energy demand, energy and investment cost, and $\mathrm{CO}_{2}$ emissions using WWR variations [39]. The optimal case served as input for a second optimization stage, using different envelope material thermal properties and brise soleil, sun spaces, as well as courtyards/greenhouses. In the first phase, a six-story cross-shaped building with 40\% WWR to the south and 45\% WWR for the west elevation was developed, saving $60.6 \%$ total annual energy demand compared to a worst-case scenario. In the second phase, the optimization of the envelope materials, sun spaces courtyard-greenhouse morphology, and the active systems deliver lower improvements: the $\mathrm{CO}_{2}$ emissions and energy cost was reduced by $23 \%$, and primary energy usage was reduced by $9 \%$. This also reinforces that geometry contributes decisively to energy efficiency. The basic geometries were selected due to simple observations of typical building shapes in Rome, and the building physics analysis provides few new ideas. While the same useful floor space and volume was considered, the dimensions of the envelopes of different shapes and their corresponding investment cost was neglected. Only single-zone thermal simulation models of multi-story blocks are calculated, which can lead to inaccurate or unrealistic results. Due to the black box character of the genetic algorithm, there are multiple hypotheses possible reasons for counterintuitive solutions. For instance, in the Mediterranean climate, high solar reflectance (SR) values, and thin insulation layers are expected for envelope materials; however, the algorithm choose low SR materials and thicker insulation to maximize winter solar gain instead of summer overheating (cooling) strategies. This hypothesis is in accordance with other literature [77].

Different variables for the width, height, and Bézier-curve of the roof gable of a greenhouse are subject to parameter optimization with the objective functions of energy consumption [90]. In the same study, a city hall's ellipsoid shape was modified through changes in the principal axes ratio of the ellipsoid, and a scaling factor was modified at one-half of the base ellipsoid in each of the five levels of the building. The energy savings were only roughly estimated. The axes ratio and arch ratio of the ellipsoid sphere geometry had the greatest effect on energy use, and the best axes ratio is 1.0-1.2 (almost rotationally symmetric cupola geometries). Orientation did not significantly influence the results. This work shows the strong impact of formal design changes on the annual energy need; however, the interdependencies were not described, making it difficult to see the processes and relevance of calculations, optimization, or building physics. 
Besides building-related properties, urban design parameters such as block geometry morphology, public spaces (sealed, water, or green areas), mixed use areas, etc. all have an impact on energy efficiency [49]. In urban BECEDO, the focus is primarily on solar energy efficiency of building surfaces [91] and the minimization of investment and operation costs of the energy system and the operational carbon emissions [49] by modifying geometry and setup of a block-arrangement in a city environment. Jérôme Henri Kämpf et al. [44] provides three different urban shape morphologies to maximize irradiation offset by thermal losses and to minimize built volume. The 'Terrace Courts' (courtyards) morphology versions performed best in energy gains and losses, due to greatest collector surfaces while the volume remained compact. Without energy optimization, another process proposes shape grammars to encode syntactic rules for morphology generation of a city quarter using GA optimization in the solutions [92].

Further study [49] reports the optimization of the 3D corner point coordinates for four simple office blocks in a city quarter. In extreme carbon scenarios, the geometries of the optimal blocks are regular, while in the in-between carbon scenarios, the geometries become more irregular (balancing solar and daylight harvesting with available floor space and orientation). Using consecutive optimization, first geometry (energy demand) optimization takes place, which is followed by the calculation of the energy system and solar potential optimization. In a "nested" optimization: geometry (energy demand) optimization takes place simultaneously with the energy system and solar potential optimization. The consecutive optimal geometries have N-S orientation, while the nested ones have more isotropic bodies. Due to these conclusions, building geometry and energy systems are mutually dependent and should be simultaneously optimized. Nevertheless, only basic block shapes were investigated in a black-box optimizer; furthermore, it is stated that certain active systems influence building shape, densities, and orientation. It is important to note here that a building design that is based on a services system choice can lead to solutions which may appear momentarily reasonable but can become obsolete due to the appearance of newer technology. Hence, the impact of active systems on a building's passive qualities should be carefully considered. J. H. Kämpf in another study optimizes urban building block configurations in three applications: cuboid buildings in an urban setting; complex building shapes adjacent to an existing house and a rectangular plan building volume (parametrized by Fourier series) [91]. The interesting and diverse applications are rather demonstrative to show the methodology.

The automated generation of optimized multi-family house layouts for minimized heating, cooling, and lighting costs and maximized living space [93] searches for the best layout and dimensions of interrelated rectangular spaces. A 2D-layout topology is generated, but the energy considerations are more or less ignored. A newly proposed energy efficient form-finder (EEF) optimization framework [40] generates 1998 optimal solutions for a multi-story office building design to reduce heating-cooling demand and thermal discomfort by generating different urban density ranges and the number of floors according to cell (space units) arranging rules, the "building modular cells" (BMC) form finding script. ORI and WWR were coupled with shape combinations. Solutions are recommended in different urban density environments for shape, set-back on site, orientation, and courtyard allocation. The results reveal that geometry significantly affects energy efficiency (7.2-37.3 kWh $/ \mathrm{m}^{2}$ a savings) and thermal discomfort reduction (12.2\%). A layout optimization of high-rise residential buildings was carried out to minimize air-conditioning and lighting energy demand [41]. T- and I-shaped buildings were generated depending on different orientation, site constraints, number and type of flats, arrangement of flats along corridors, rotation angle of wings, and accessibility (fire exits). Here, 13-33\% electricity savings were achieved due to geometry optimization of the flat and building wing (high-rise layout and hence shape) configurations, orientation, and natural ventilation. 


\section{Algorithms in BGDV including BECEDO}

The type of problem and the mathematical description required fundamentally influence the performance of optimization algorithm(s). This has led to a large number of methods being developed over the last two decades in BECEDO projects. With whole-building simulations, algorithms require significant processing resources (time and hardware). It makes sense to simplify the problem of a large search space and to execute sensitivity and uncertainty analysis first, and later switch to the optimization procedure [13].

Most of the applied algorithms in BECEDO can be put into three groups: evolutionary algorithms (EA), derivate-free algorithms, and hybrid algorithms (which are a combination of the first two) [9]. Evolutionary algorithms (EA) were present in more than $66 \%$ of the evaluated literature and were dominated by genetic algorithms (GA) and hybrid GA $[8,12,18,27,29,31,36,38,40,46,66,89]$ (Figure 1). GA is mostly used for global searching and is suitable to find the optimum of non-linear problems with discontinuities (discrete values) [12] and many local minima. It requires significant sample data, which will be rejected later, since they are not near-optimal or non-dominated solutions. Significant simulation resources are required due to the high number of cases.

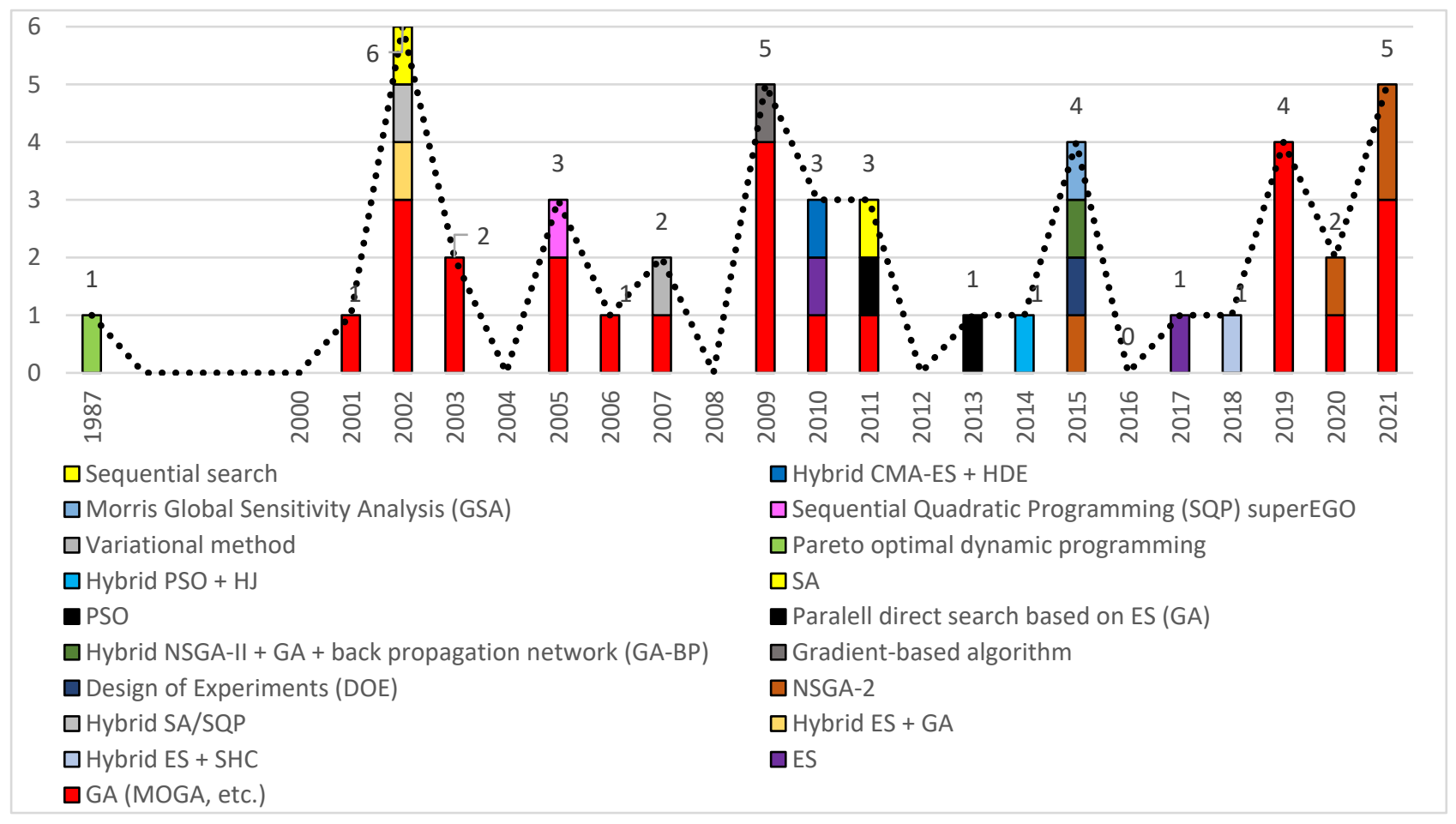

Figure 1. Number of applied optimization algorithms in BECEDO studies in chronological sequence.

To solve this problem, often, simplifications (reduction in populations) are deployed (with having the thread to lead to non-optimal solutions) or modifications in multimodal functions, transformation of fitness function, effective selection mechanisms, ranking, partitioned GA, and niching are used. The divided populations and runs are promising, but there is a thread of too similar convergences, and the optimum may be missed. The random character of the GA search process cannot guarantee finding the optimum solution after a finite number of iterations [8]. Further, GA provides only a near-optimal solution, and in many cases, it does not even reach near-optimum [94].

The random initial population and the stochastic operators cannot guarantee better solutions than common design practice. While the local optimizer is generally efficient, it is unable to manage discrete variables; hence, good custom solutions should be assumed by experience-based design practitioners at the starting point, or a run of previous global search is recommended [13]. Another limitation is that the final solution may still not be the 
optimum, since it is difficult to prove the optimality due to the integral properties of GAs. The GA optimization approach acts like a black box, and the designers cannot monitor the background processes [78].

Current trends shift from GA to non-dominant sorting genetic algorithms II (NSGAII) $[6-9,11-13,23,31-33]$ or multi-objective genetic algorithms (MOGA and MOGA-II), because they are more suitable for MO search problems, typical in building design [8,9,11,95-98]. Ghada Elshafei et al. [84] looked for the optimal green arrangement's models, procedures, and parameters utilizing GA innovations. The GA-NSGA-II along with integrated GA was also considered to be more accurate at predictions. Further approaches were incorporated as well, e.g., neural network (NN), simulated annealing (SA), fuzzy set theory, decisionmaking multicriteria, and multi-objective programming. The author states that the GA combined schemes can fulfill all the requirements for finding optimality for multi-objective problem-solving.

The rest of the non-genetic algorithms consists mostly of a low number of particle swarm optimizations (PSO) [95] as part of the EA domain, and derivate-free, direct search algorithms (e.g., hill climbing method, Hooke-Jeeves HJ) and hybrid combinations (Figure 1). Direct search algorithms search the solution space using heuristic rules, needing continuous objective function without derivate calculation. They are more robust against noisy functions and can deliver good solutions in the case of small cost function discontinuities and when small local optimum is handled. Hybrid algorithms can reach better optimization performance compared to single algorithms, but the advantages depend strongly on the combination of the algorithms, objective function, constraints, control parameters, etc. of the particular problem $[9,95]$, making it difficult to categorize them. The regular process applies an EA as the global search algorithm to detect a nearly optimal solution; thereafter, this serves as the initial point for a direct search local optimizer. The effectiveness of this combination is high.

Regrettably, algorithms are mostly carried out without thoroughly considering their effectivity and efficiency performance. Farshad Kheiri provided a comprehensive review about the performance of diverse optimization algorithms in the building energy domain [12]. It is difficult to derive generic recommendations about the performance of each optimization algorithm, since the performance of the algorithms differ from task to task, depending on the characteristic of the problem. Modifying the number of variables or the coarseness of the objective function, for instance, can cause outperforming of particular methods with each other and vice versa. However, eight criteria were considered when deploying an optimization method. Robustness in finding the optimum as in [95], and additional robustness in the assessment; efficiency including computation time and memory; accuracy; single or multi-variable containing low (one or a few variables) or high-dimensional (high number of variables) tasks; single or multi-objective nature of a problem; local or global optimization nature of problem; discrete or continuous variables as building parameters can be both discrete (e.g., number of floors, walls, shadings, etc.) and continuous (e.g., geometry metrics as length, area, volume, etc.). Continuous values can be derived by systemizing according to concrete steps, for example, size. In the work of Binghui Si et al. [95], six performance indices were defined through equations to benchmark MOGA-II, HJ and MOPSO: stability (consistently finding the optimal solution in the same test repeatedly), robustness (find the optimal solution even when control settings change), validity (finding the true optimal solution within a limited amount of objective function evaluation), speed (convergence rate to the optimal solution), coverage (ability to search in the entire feasible solution space), locality (ability to fine-tune around the near optimum to reach true optimum). In a DOE medium office building test window positions, orientation and thermal properties of the opaque envelope were optimized, revealing that MOGA-II and MOPSO were generally better performing despite the locality [95]. Attention and proper knowledge are required to carefully choose the appropriate optimization method based on the nature of the problem and the features of the method (pros and cons of performance indices) so as to not search for a local rather than global optimum. 
The performance of the algorithms is also dependent on the simulation software. The smoothness of the cost function in simulations enable the application of numerous more efficient algorithms [13]. As in building performance simulation, the properties and conditions are often non-linear and discontinuous [8], so the available algorithms are not able to guarantee true optimum solutions, since most of them require cost function smoothness. Therefore, the desired algorithms should not need to calculate derivatives such as the probabilistic evolutionary and deterministic direct searches.

\section{Discussion}

\subsection{Prevailing Trends in Building Shape Optimization}

The present optimization studies that contain BGDVs represent an important first step towards the introduction of the building shape as an optimizing factor. Many of the investigations reinforce that geometry does contribute decisively to energy efficiency, and therefore, geometry-related design changes have strong influence on the annual energy demand.

Nevertheless, after analysis of the previously presented literature (Sections 2 and 3), the current status quo reflects a series of shortcomings, regarding how the BGDVs are considered in the optimization process. As the complete energy, comfort, and environmental criteria are still not integrated and analyzed in a comprehensive manner in BECEDO models, there is a trend towards integrating all these fields into diverse engineering and mathematical methods [32]. Since the calculation models and their interoperability are complicated, BGDVs remain relatively oversimplified. Architectural design involves parameters that cannot be easily quantified; hence, it is an ill-defined problem [12]. To enable algorithmic optimization of mass and form, all necessary variables should be described mathematically, which is a challenging task: a rectangular cuboid body needs more than 10 variables and more complex shapes increase the amount of variables significantly [9]. This is reflected in the previous literature analysis: building form is more or less neglected, i.e., only taken into account at rudimentary level.

The studies are commonly restricted a limited number of easy-to-calculate BGDVs as simple sizes: wall dimensions, spaces or wing depth, roof sizes, height, floor stacking, as well as ratios of geometry dimensions, e.g., aspect ratios, A/V ratio, or relative compactness. All these variables describe the dimensional properties of the shape, but they lack information about the concrete form of the geometry, i.e., the position of the surfaces, corners, edges, or the location of the room units relative to each other and relative to a reference space (e.g., coordinates). The typical chosen shapes are simplified rectangle and cuboid geometries.

Mostly, the focus is on the demonstration and validation of the proposed technique, methodology, algorithm, or software, as well as the tradeoff between diverse targeted results. Characteristically, most of these papers demonstrate their proposed method and apply it using a simple example. This is undoubtedly crucial; however, this means that geometry remains in the background most investigations [51,95]. Additionally, the focus is set on some certain BEDV and HVAC system parameters instead of addressing the whole design process of a building, specifically the shape optimization. Therefore, the role of BGDVs in BECEDOs fades into the background.

It is also common that only basic simplified shapes are calculated in oversimplified simulation models, leading to possible inaccurate results. Another typical phenomenon is the lack of information on the relationship between geometry properties of the tested building designs and their building physics effects or how they influence the results. The shapes are frequently gained by random changes and a combination of geometry-size values by the GA. Due to the black box character of GA, counterintuitive solutions are made by the algorithms, which are justified only by probable hypotheses. In addition, due to intense building simplifications and the fact that the studies mainly focus on the optimization technique, most of the results are already well known by an experienced 
building energy designer, making the conclusions of the building physics and building design rather questionable.

Besides the above general trends, the reviewed research work that employs simple geometry modeling (Section 2.1) has further specific characteristics. Most of the cases are made using simple base shapes and/or small-scaled building examples. Different versions of the building shapes are created by modifying the initial building model and manipulation of the dimensional properties. However, the range of changes in the experiments are very limited to minor numerical modifications without exploitation of the full parameters. The concluded recommendations for BGDVs are mostly proposed dependent on various climate zones, for instance, advantages and disadvantages of different depth, roof properties, and aspect ratio in heating or cooling climates. Furthermore, the results are limited to a specific initial framework of one or a limited number of input geometries.

Characteristically, the research results are still complicated and ambiguous for design teams, which are usually led by architects and urban designers. Most of these studies have developed analytical forecasting frameworks to predict and evaluate building performances, which are not based on real constraints and not applicable in practice for designers. The results of the optimizer algorithms are mathematically sound (e.g., Pareto frontier methods, interrelationship-ratios, etc.); however, they are not easy to interpret into actual building design tasks. Although easier for scientists, most of the mathematically sound results are difficult or impossible to retrace and understand for design professionals, and thus, results remain impractical for further design steps.

Choosing the appropriate objective function and design variable plays a key role in optimization projects [13]. Regardless of the advancements of the optimization techniques, the output and success of the overall optimization process strongly depends on the designer/developer/researcher-defined input parameters, design variables, constraints, objective functions, etc., as well as the designers expertise with fine-tuning the optimization parameters [12]. However, the selection of options, constraints, and design variables in literature - often with help of sensitivity and uncertainty analyses—shows a greater diversity compared to real-world boundaries. Without neglecting the probability of exploring new, innovative design supporting interdependencies, a great number of the solutions does not seem to meet the needs of industry design practice appropriately. Numerous options can be limited due to building codes, local site-specific boundaries, and the requirements client. The available studies are mostly based only on literature sources, and they are not able to propose comprehensive rules on the selection of design variables and objective function.

The examined literature that applies advanced building shape modeling (Section 2.2) represents a predictable development stage in BGDV-considerations, trying to reach the objective functions using more elaborate and complex shape variations. However, some investigations tend to create complicated, abstract shapes, and do not take into consideration that these impractical forms require significantly higher construction and material costs, combined with a higher LCA impact. Some effort is now being made to create rule systems for code building geometry generation by arranging space unit cells or building parts to assemble complete building shapes. This represents the most fundamental step in the implementation of building geometry into BECEDO.

A prevalent tendency emphasizes that the building envelope and/or services systems would 'overwrite' the importance of the shape regarding energy and comfort performance; however, that is only true when the configuration of more passive and active design variables (shape, envelope, and HVAC system parameters) are simultaneously taken into account during the optimization process. Thus, numerous studies address the mutual dependency of shape and further building systems and simultaneous optimization. However, this consideration fails to recognize that the mass shape is not only the most essential and inherent outcome of the desired space organization, but it is also the first and inevitable 'product' during the early sketch plan stage for the creation of a building. If the energy and comfort optimization of the building body already takes place during this initial phase, 
significantly less effort is required in subsequent design steps to improve further passive and active variables. Initial shape optimization (geometry design modifications during planning) requires considerably less expenses compared to later material and HVAC investments in construction and operation (LCCA); therefore, building geometry directly influences energy design. As a first step, through optimization of the form, significant energy and comfort improvements can be achieved, enabling significantly lower efforts on subsequent development of the thermal properties of the envelope, HVAC and lighting systems, automation of operations, etc. A shape with lower energy demand can allow higher thermal transmittance envelope structures and less mechanical systems, for instance. Therefore, the design and implementation of more expensive technological systems, in terms of LCA and LCEI impact, should not overwrite the geometry, as the primary architectural-functional premise. This consecutive optimization process is supported by other literature [39].

The perception that certain active systems influence the effect of, for example, building shape, densities, and orientation is only true if it is considered together with the following observation. A building shape and passive design that relies heavily on engineering service systems can lead to solutions, which may appear reasonable at the time but can easily become obsolete with the emergence of new technology. Regarding the building life cycle (approximately 100 years) versus a HVAC system (depending on the system approximately 15-25 years) the active systems impact on a buildings passive measures should be carefully considered and evaluated for optimal design decisions.

It is also important to note that the translation of a real-world architectural design problem into a mathematical domain comes with several limitations and the application of commonly used optimization algorithms in building design problems can only provide advanced combined solutions but will be unable to guarantee the optimal solution. The stochastic behavior of the most frequently applied evolutionary technique in BECEDO, the plethora of the configurations, and the numerous building related design problems make it difficult to draw definite conclusions about the performance of these algorithms [12,13].

No standards exist to prove of reliability or robustness of the optimization results. For instance, a brute force exhaustive search is applied to check the validity of the optimum solutions (Genopt [99]) or detailed EnergyPlus model comparison to surrogate models [100]. The application of BECEDO in real-world design tasks is still at an early stage [8].

\subsection{Frequently Applied BGDVs in BECEDO}

Figure 2 categorizes studies from 1987 to 2021 into research utilizing different BGDVs. Overall, 30 BGDVs could be diversified (orange and red colored), and two further classes are assessed additionally, representing BEDVs (light grey colored) and ADVs (dark grey colored) as well. All variables are simple sizes and dimension properties, together with some basic ratio values. The red bar, showing the most frequently used BGDVs (which are applied more than 5 times), mainly in the last two decades, incorporate aspect ratios, height/stacking, depth of space or wing, wall and floor sizes, and roof parameters. Among the applied BGDVs, this group of six variables are most capable of describing the building shape effectively-an obvious reason for their popularity in the investigations. The variables of shape factor and relative compactness describe the energy performance (heat loss) of the geometries. The remaining 22 BGDVs are strongly related parameters to the specific research they belong to or support a few first urban scale BECEDO experiments (e.g., perimeter to urban area ratio, spacing between blocks, building height to street ratio). 


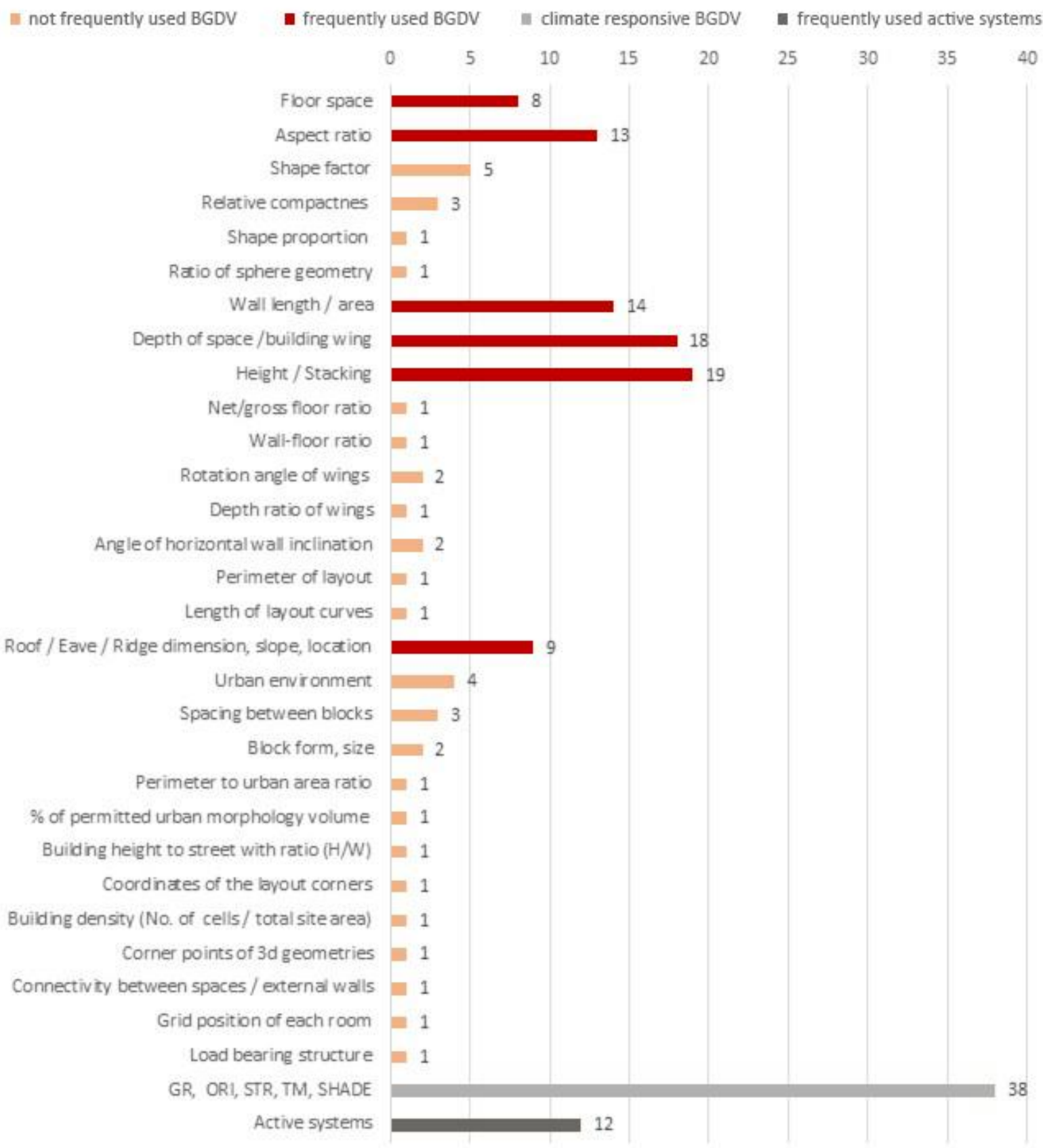

Figure 2. Number of publications (1987-2021) applying BGDVs in BECEDO research.

The BGDVs are combined with BEDVs in almost all publications, thus the high number of BEDV applications.

The most frequent used BGDVs (red bar in Figure 2) together with the energy efficiency related BGDVs (shape factor and relative compactness) are assessed in chronological order in Figure 3 and Table 3 to display trends in the application frequency of the shape variables in BECEDO-s. From 2020, the number of BGDV applications is growing again (first peak application in 2002), with the characteristic use of roof dimensions, height/stacking, depth of space, façade sizes, and aspect ratio variables in the investigations. From the beginning of the last decade, an increasing trend utilizes these BGDVs. The assessed BGDV distribution clearly shows that the variables only give information about the dimensions of the shapes, and there is a lack of variables, which would be able to describe a specific building form in terms of exact location or coordinates of spaces and building parts, corners, and edges, respectively. 
Table 3. Research focusing on frequent and significant energy performance related BGDVs in chronological order.

\begin{tabular}{|c|c|c|c|c|c|c|c|c|c|c|c|c|c|c|c|c|c|c|c|c|c|c|}
\hline $\begin{array}{l}\text { Shape Significantly } \\
\text { Describing BGDVs }\end{array}$ & 1987 & 1990 & 2001 & 2002 & 2003 & 2005 & 2006 & 2007 & 2008 & 2009 & 2010 & 2011 & 2012 & 2013 & 2014 & 2015 & 2016 & 2017 & 2018 & 2019 & 2020 & 2021 \\
\hline Floor space & [61] & [57] & & [58] & [66] & & & & & & & & & & & [75] & & [60] & & [41] & & [82] \\
\hline Aspect ratio & [61] & & [62] & & & [67] & & & & & [88] & [89] & & [73] & [74] & {$[46,75]$} & & [60] & & [77] & [78] & [80] \\
\hline Shape factor & & & [6] & & [42] & [48] & & & & & & & & & & [76] & & & {$[55]$} & & & \\
\hline Wall length/area & & [57] & & $\begin{array}{c}{[58,63,} \\
64]\end{array}$ & [65] & {$[68,69]$} & & & & {$[7,72]$} & & & & [54] & [74] & & & [60] & & [41] & & [79] \\
\hline Depth of space/building wing & & [57] & & $\begin{array}{c}{[58,63,} \\
64]\end{array}$ & $\begin{array}{l}{[42,65,} \\
66]\end{array}$ & [69] & & & & [7] & [88] & & & {$[54,90]$} & [74] & & & [60] & & {$[41,50]$} & & {$[79,82]$} \\
\hline $\begin{array}{c}\text { Roof slope/Eave/Ridge } \\
\text { location }\end{array}$ & & & [62] & [64] & [65] & & [45] & & & & {$[44,91]$} & & & [73] & & [46] & & & & [50] & & \\
\hline
\end{tabular}




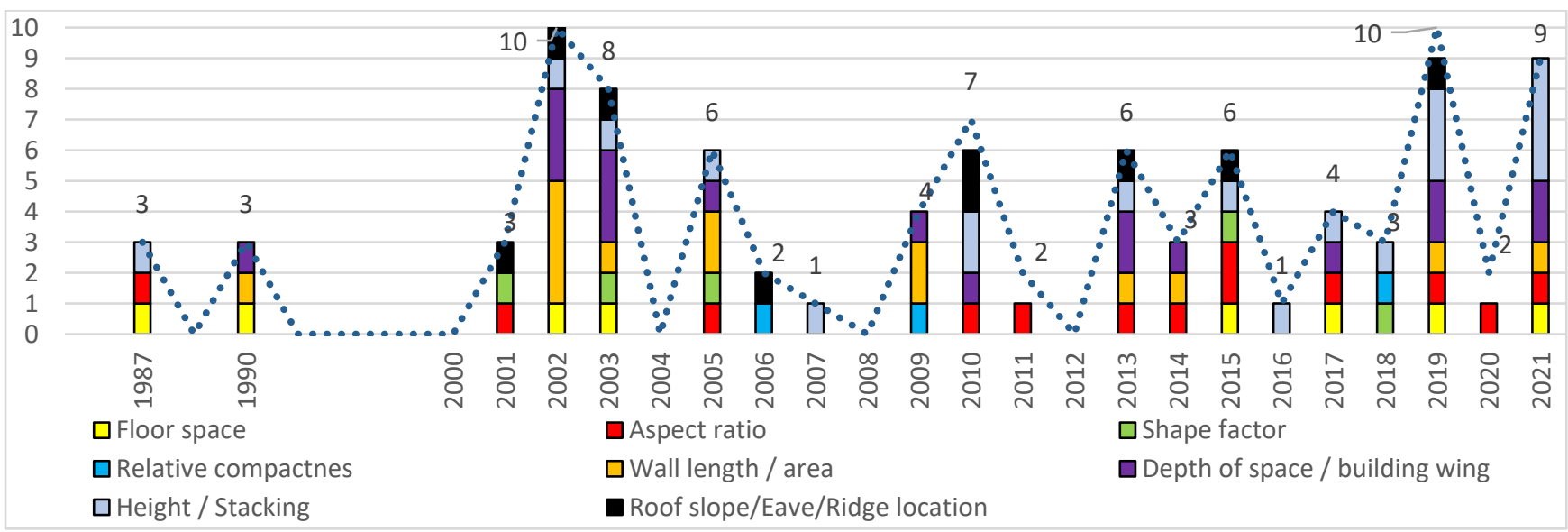

Figure 3. Frequent and significant energy performance related BGDVs in chronological order.

\subsection{Principles of Building Geometry Modeling in BECEDO Processes}

After evaluation of the BECEDO literature (Section 2), flow charts were created to visualize the different shape modeling methodologies used. Upon final analysis, all applied and/or developed geometry modeling techniques could be according to two main modelling principles: shape modification and the shape generation. Figures 4 and 5 display schematics showing the generic modeling techniques. Most of the studies employ shape modification, using BGDVs at a basic level of complexity $[1,7,37-39,44,49,50,61-65,67,68,70,72-$ $82,88,90,91]$. The remaining investigations introduce shape generation, using BGDVs at an advanced level of complexity $[40,41,93]$.

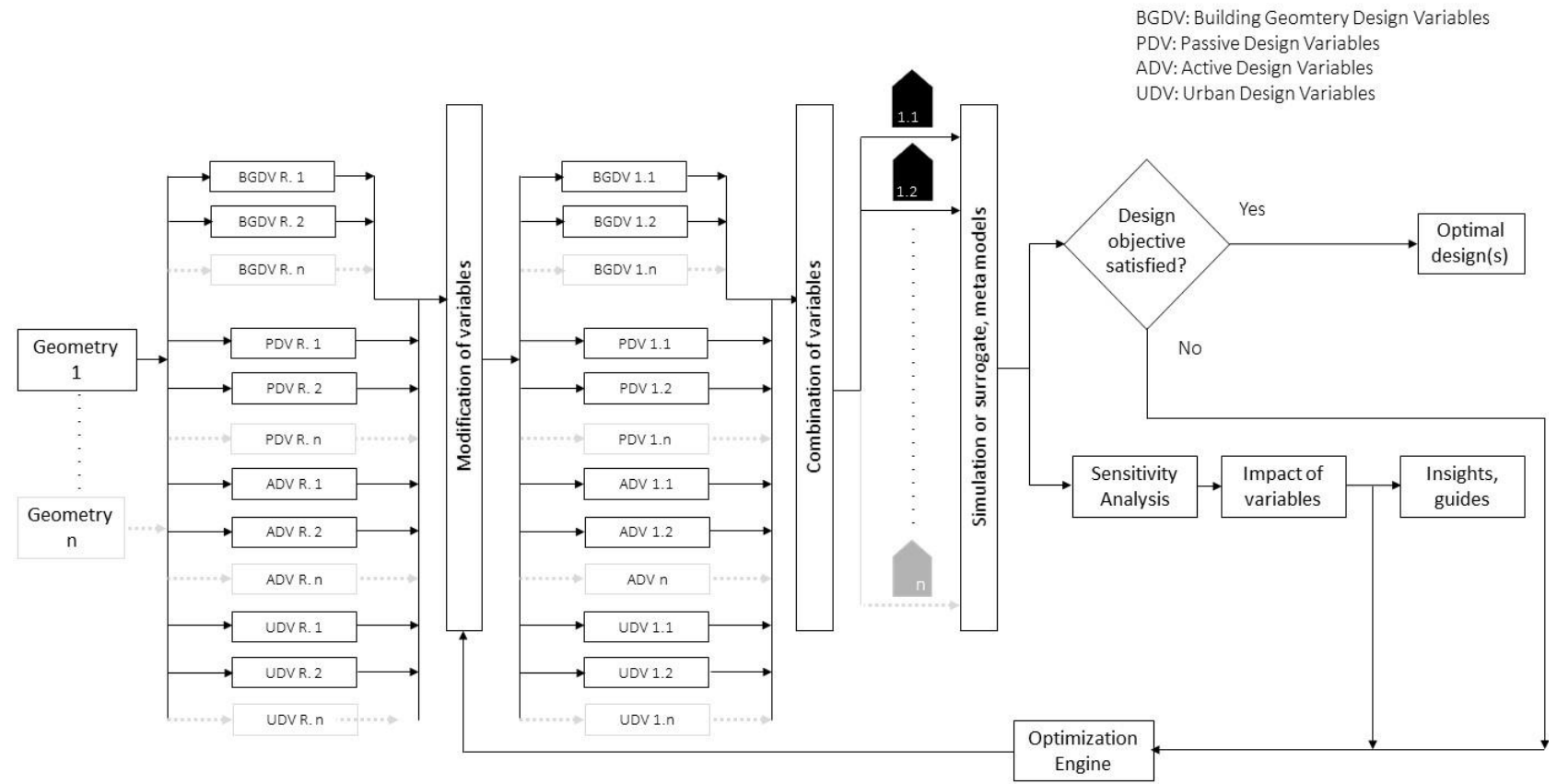

Figure 4. Flowchart showing the basic principles of building shape modification methodology in BECEDO processes. 


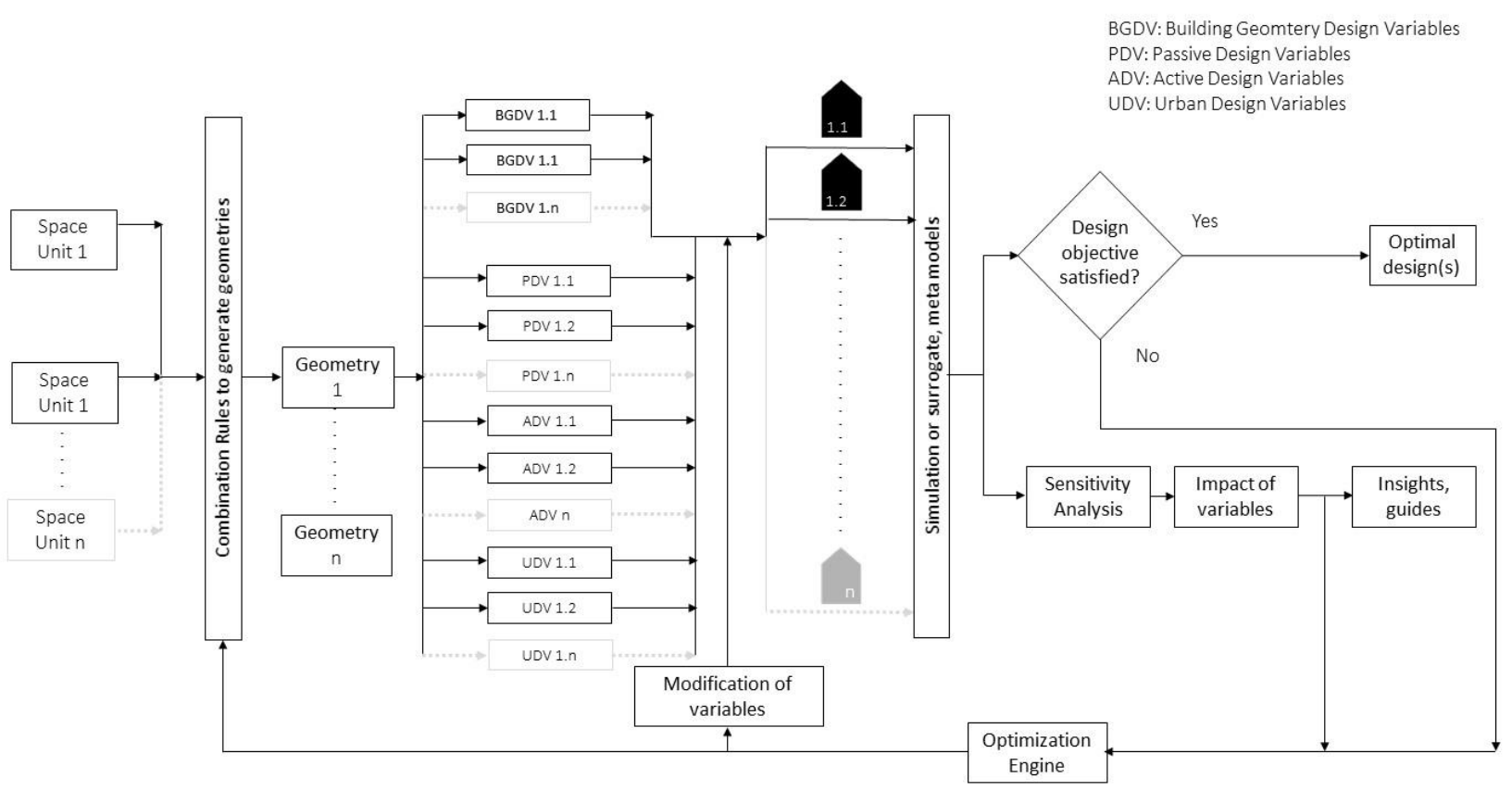

Figure 5. Flowchart of the basic principle of building shape generation methodology in BECEDO processes.

Shape modification can be characteristically broken down according to methodology used (Figure 4): Depending on the particular design task, one or more initial building designs is proposed by the planner. Spaces are elaborated by selecting a limited number of mostly oversimplified, basic BGDVs, which are easy to assess and apply in simplified building shapes (e.g., aspect ratio), complicated algorithms, and calculation models. These shapes are predefined, based on statistics, codes, standards, and guidelines, as well as own concepts, rules of thumb, or passive design principles. They are often common shapes, but sometimes, unusual geometries are deployed as well to widen the sample range. Depending on the type of research, these BGDVs are combined with BEDV, passive and active design variables (PDV, ADV), as well as with urban design variables (UDV), and in this way, input data are produced allowing the modification of these parameters. After modification, the changed variables enable different examples with new shape versions (and further passive and HVAC system combinations). Next, building physics and LCA performance values are assessed via thermal, daylight, and in some cases, CFD simulation engines or surrogate prediction models (e.g., ANN, regression models, etc.). The calculation results serve as input for the evaluation (by the computer) whether the predefined objective functions are approximated or met. If yes, the optimal design is created; if not (i.e., the result values still do not reach the optimum target sufficiently), an optimization engine (algorithm) is responsible for modifying and combining variables for new design variants until the objective functions are met. Additionally, sensitivity analyses are carried out at a different level of resolution, partly to support the optimization engine (give feedback about the design variables' impact on the objective function) and partly to gain insights and conclusions for design guides/recommendations.

Shape generation is similarly based on a relatively common methodology, as demonstrated in Figure 5's flowchart. In principle, a constraint or rule system is achieved first to combine and arrange diverse space units, rooms, apartments, or wings of a building (or urban design) and, as a result, to generate a diversity of building shapes. Thereafter, the building geometries will be combined with PDVs, ADVs, and in some cases, with UDVs, creating complete building cases for the subsequent building physics and environmental calculations (simulation engines, meta-models, surrogate predictions). From this stage on, the steps are basically identical with the geometry modifying method (Figure 4). 


\subsection{Categorization of Building Geometry Modeling in BECEDO}

From 2000 onwards, there has been a gradual tendency of BGDV including BECEDO investigations where building shapes are linked to the energy, comfort, and environmental performance feedback during the optimization process (Figure 6). Overall, 90.6\% of the BECEDO studies belong to the shape modification modeling category, deploying simple levels of BGDV-complexity (yellow bar) advanced level of BGDV optimization (light brown red bar) by modification. Within the shape modification category, most research $(72.4 \%)$ considers geometry at a on basic level of complexity with a limited number of variables with simple geometries, etc. (see Section 4.1 ). These studies are $65.6 \%$ of the total studies, and they modify one or more (i.e., a limited number) of the base building geometries in order to handle 'building shaping'. New shape variants are generated by the modification of some numerical parameters of the already existing geometry properties of the reference model(s) as dimensions and ratios for instance and further passive (e.g., BEDV) and active (e.g., HVAC) system parameters.

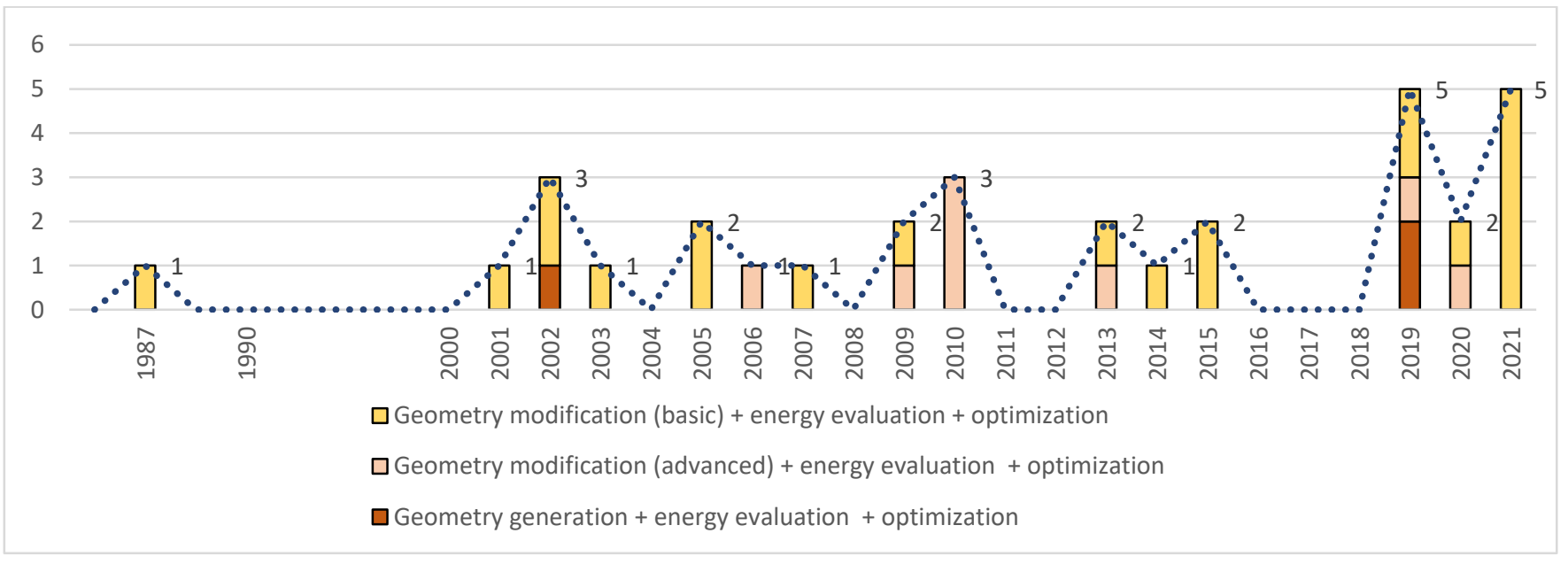

Figure 6. Studies with geometry modification and geometry generation with and without energy evaluation and optimization in chronological order.

Within the shape modification category, $27.6 \%$ of the studies address geometry considerations on a detailed level. This modeling category is $25 \%$ of the total shape optimization including BECEDO studies.

Overall, 9.4\% of all screened BGDV including BECEDO studies represent the modeling category of shape generation, expanding to complete, more or less comprehensive geometry creation during the optimization process. These allow the initial efforts to generate a series of new geometries; then, after calculating the performances re-generation of the shapes and/or modification of the shape properties (and other passive and active systems), it is possible to find the optimum solution. This latter group (a total of three studies) represent the most developed BGDV based optimization. Figure 6 and Table 4 clearly show the lack of research, which implements architectural space organization and shape into BECEDO.

After evaluation of the literature, a series of building geometry modeling categories can be defined, providing various approaches for how geometry is treated and the level of complexity. The following geometry modeling categories propose diverse building space organization and shape defining solutions. Besides modeling techniques in BECEDO work (see also Section 4.3), further modeling categories were established, which do not include optimization; nevertheless, they represent important development stages in the evolution of BGDVs in research related to sustainability. 
Table 4. Research focusing on studies with geometry modification and geometry generation with and without energy evaluation and optimization in chronological order.

\begin{tabular}{|c|c|c|c|c|c|c|c|c|c|c|c|c|c|c|c|c|c|c|c|c|c|c|}
\hline & 1987 & 2001 & 2002 & 2003 & 2004 & 2005 & 2006 & 2007 & 2008 & 2009 & 2010 & 2011 & 2012 & 2013 & 2014 & 2015 & 2016 & 2017 & 2018 & 2019 & 2020 & 2021 \\
\hline $\begin{array}{l}\text { Geometry generation + energy } \\
\text { evaluation + optimization }\end{array}$ & & & [93] & & & & & & & & & & & & & & & & & {$[40,41]$} & & \\
\hline $\begin{array}{l}\text { Geometry modification (advanced) + } \\
\text { energy evaluation + optimization }\end{array}$ & & & & & & & [1] & & & [38] & {$[44,88,91]$} & & & {$[90]$} & & & & & & [49] & [39] & \\
\hline $\begin{array}{l}\text { Geometry modification (basic) + } \\
\text { energy evaluation + optimization }\end{array}$ & {$[61]$} & [62] & {$[63,64]$} & [65] & & {$[67,68]$} & & {$[70]$} & & [7] & & & & [73] & [74] & {$[75,76]$} & & & & {$[50,77]$} & {$[78]$} & [37,79-82] \\
\hline
\end{tabular}


Shape generation without energy evaluation and optimization.

- An agent-based topology finding system creates layouts as a topology finding process, generating sphere and capsule bubble agents. Interaction rules as attraction, repulsion, swap, and compression help to generate multi-agent systems as layout schemes. The developed software allows connected rooms (agents) to be dragged closer and unconnected rooms push each other away if close enough. A 3D grid-system based on rectangular cells converts the multi-agent layout into a space model [60].

Shape modification with energy evaluation.

- Changing of diverse BGDVs.

- Modification of geometry and setup arrangement for urban blocks. Four- and eightstory simple prismatic building block morphology versions [63].

Shape generation with energy evaluation.

- Shape grammar (converted into a parametric system). Variants programming: translating shape transformations (scale, reflection, translation, rotation) into equations and variables. Every room is modeled as a block with changeable aspects ratio, length, width, shape, size, and location. Automated energy evaluation of created forms [54].

- Generation of a large number of building geometry alternatives using "Evolutionary Program for Space Allocation Program" (EPSAP), including GA. A floor plan representation scheme, including total area for each story, construction area, circulation space area, and openings is randomly generated, and then the energy performance is calculated [55].

- "Building Modular Cells" (BMC) geometry generation technique is introduced to generate urban morphology based on a grid raster with various urban density building categories, building height classes, and urban patterns (street area between the building blocks) and a form generating algorithm, including architecturally eligible form selection. Space-units (modular cells) are arranged due to the form generation rules [56].

Geometry modification with energy evaluation and optimization-simple complexity.

- Changing of diverse BGDVs.

Geometry modification with energy evaluation and optimization-elaborate complexity.

- Changing of diverse BGDV-s

- Automated generation of 2D-layout and topology. Finding the best location and size of interrelated rectangular spaces. (1) Swapping the positions of two space units, (2) reallocation of positions, and (3) reducing the size of a space unit. Constraining overlapping, regulating connections of spaces, paths and access ways and the building envelope [93].

- $\quad$ Settlement scaled building block morphology optimization for solar energy use (heating, lighting). Diversely oriented building rows and courtyard block arrangements tested [44].

- A hybrid evolutionary algorithm is applied with constraint handling as an optimization method for urban building configurations. Urban block grid density (no. of blocks) and height optimization. Complex extension building and roof shapes adjacent to an existing house); rectangular, planned building's volume, parametrized by Fourier series [91].

- Optimization of the geometry of simple office building blocks (energy demand) in a city quarter. Optimization of the horizontal and vertical positions of corner points [49].

- Geometry optimization of common linear (I), L- (L), court (O), C- (C), T- (T), H$(\mathrm{H})$, cross $(\mathrm{X})$, and Y-shaped $(\mathrm{Y})$ buildings (LOD 100). Multiple geometries with shape proportion (depth of the space/wings) modification as a 'gene' under the same volume [39]. 
Geometry generation with energy evaluation and optimization.

- "Building modular cells" (BMC), custom developed geometry generation technique based on a $4 \times 4$ grid raster to search for optimum solutions in five high-rise office buildings in five urban density (UD) areas. Space-units arranged according to combination rules [40].

- GA generates layouts in two phases: combination of different wings (rotation angle) to form the shape and arrangements of flats into the wings [41].

The diversity found in these modeling techniques demonstrates that the treatment of building geometry in scholarly work is still in its beginning stages, with the various modeling techniques resulting in different prototypes, making it difficult to see any trends in the methodology. Unfortunately, the most promising studies, which use BGDVs, which facilitate automated energy and comfort simulations and evaluate results, do not carry out optimization. Within BECEDO research, the last two examples of geometry generation with energy evaluation and optimization are the most advanced examples. These studies rely on arranging space units into complete buildings, which feedback from BECEDO that directs the space generation process.

\subsection{Optimization Result Improvements in BGDVs Containing BECEDO}

Figure 7 shows the percentage of improvements in the reviewed work according to the different objective functions. It is worth mentioning that not only BECEDO but also BECED studies were evaluated, since they provide valuable insight into geometry related environmental savings. Unfortunately, the number of BECEDO works, which provide well defined improvements in the results is very low. Among 45 evaluated BECED and BECEDO studies, only 17 papers contained content related to quantified effects (improvements) related to the initial case. Most studies assess energy-related improvements, while comfort and environmental progressions are less frequently quantified as a metric of a research's success. The major part of the BECEDO efforts deal with the impact of design variables on the objective function as a kind of SA or only indicate a general, approximate effect or trend of their optimization or SA framework. The highest energy related improvement (over 60\%) is achieved by the optimization of the building geometry (shape proportion) in combination with BEDV (WWR, ORI). A high degree of improvement (80\%) in environmental savings was also possible including non-renewable cumulative energy demand due to aspect ratio, $\mathrm{BEDV}$, and active system optimization. Comfort as a targeted optimization objective is hardly touched, and further research is necessary. The improvements in the three objective functions are, in all the studies, a result of simultaneous optimization changes in the geometry as well as additional passive and active systems; therefore, it is not possible to evaluate the exact effect of geometry optimization (or other design variables). Instead, Figure 7 gives information about the status of development improvements, where BGDVs contributed to the optimization procedure. The energy and environment related improvement values are significant in more than $50 \%$ of the assessed studies, making BGDV a promising contributor in BECEDO.

The available studies carried out investigations in multiple locations, covering a wide range of different climate conditions. Though building shape performs differently in different climate zones [83], it has significant effect on the BECE performance for all climate territories, from cold to warm climates. Since geometry generally plays a key role in all climatic circumstances, the current review did not separately assess the criteria of climate but focused more on the role of geometry and its variables in the optimization process.

It is important to mention that validation of the calculated results against measurements, reference data, literature, etc. is only found in four of the studies evaluated $[6,40,56,76]$. 


$$
\begin{aligned}
& \text { Energy saving due to Aspect ratio, Height / Stacking + BEDV (Yigt, } \\
& \text { 2021) } \\
& \begin{array}{c}
\text { Exergy efficiency increase due to Heght / Stacking, Spacing between } \\
\text { blocks, Block form, size, Per meter to urban area ratio (Mert, 2016) }
\end{array} \\
& \text { Reduction of heat load due to Corner points of 3d geometrie, Grid } \\
& \text { position of each room (Yi, 2009) } \\
& \text { Sola energy utilization due to Height / Stacking, Roof geometry, } \\
& \text { Volume (Kämpf, 2010) }
\end{aligned}
$$

Energy Use Intensty (EUI) decr easing due to Depth of space / building wing, Roof slope / Eave/ Ridge location + BEDV (Fang, 2019)

Cooling ene gy saving due to Heght / Stacking, Urban environment, Build ing height to street width ratio (H/W) (Javanr oodi, 2018)

Heating energy saving due to SF + BEDV (Aksoy, 2006)

Monthly energy consumption reduction due to Floor space, Wall length / area, Depth of space/ building wing, Heght / Stacking, Rotation angle of wings + BEDV (Gan, 2019)

PV energy product ion increase due to Rotation angle between wings, Depth ratio of wings, Spacing between blocks, BEDV (Hachem, 2011)

Total energy consumption reduction due to SF + BEDV (Yu, 2015)

Total energy saving due to Shape proportion (SP), Geometry generation with energy evaluation +BEDV (Cia diello, 2020)

Thermal discomfort time decrease due to Geometry generat ion with energy evaluation, Height / Stacking, Ur ban environment, Building height to street width ratio (H/W) (Javanroodi, 2019)

Useful Daylight Intensiti (UDI) incr easing due to Depth of space / building wing, Roof slope / Eave/ Ridge location + BEDV (Fang, 2019)

Life cycle environmental impact (LCEI) reduction from operation and due to Aspect ratio + BEDV (Wang, 2005)

CO2-eq emission reduction due to Aspect ratio, $\mathrm{HVAC}$ / energy system + BEDV (Ciardiello, 2020)

Lifecycle environmental impact (LCEI) reduction due to Aspect ratio + BEDV (Wang, 2005)

Environmental savings (EN 15978 + non renewable cumulative energy demand (CED) due to Aspect ratio, HVAC / energy system + BEDV (Kiss, 2020)
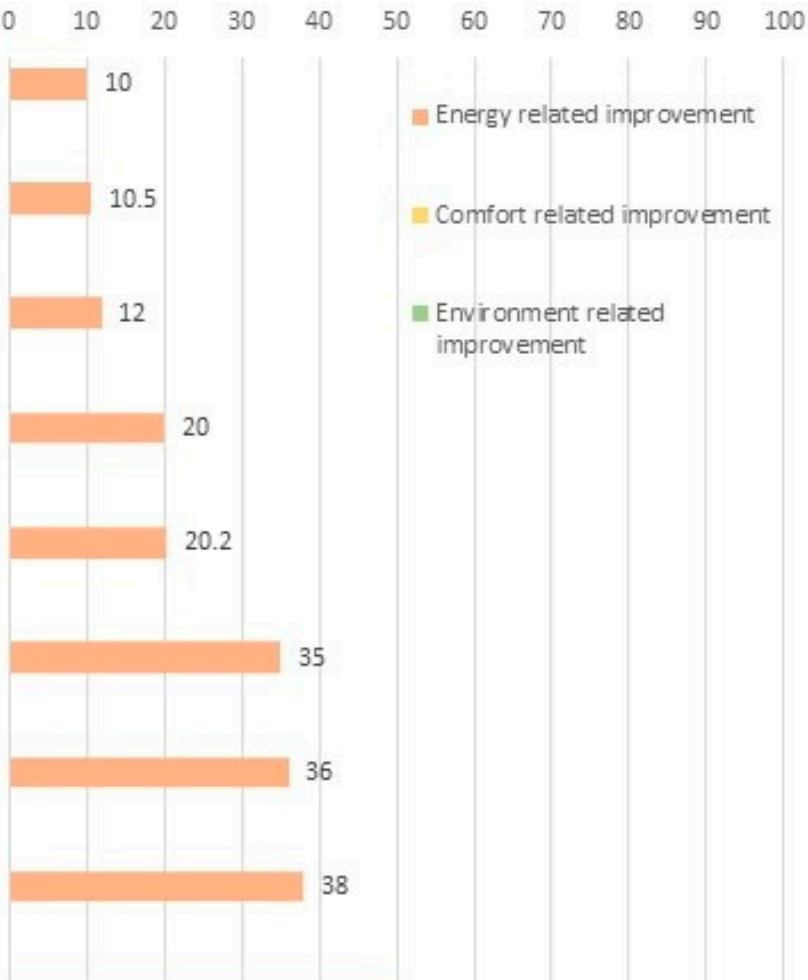

Energy related improvement

E Comfort related improvement

Environment related improvement

50
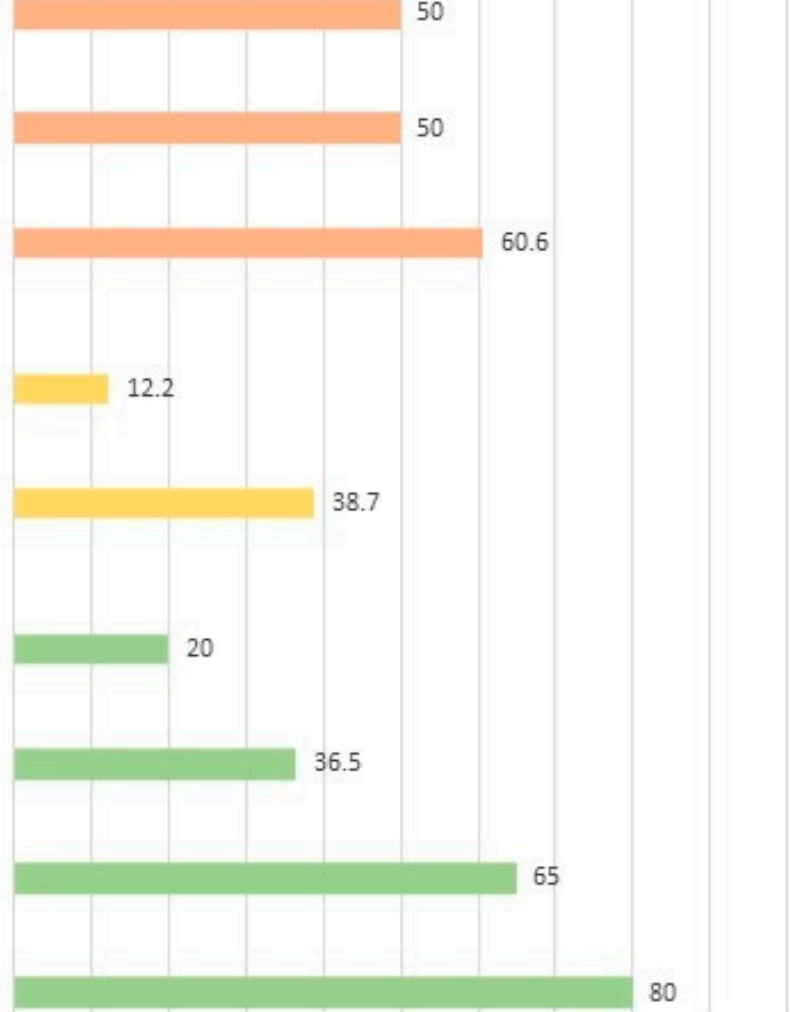

Figure 7. Improvements (\%) in energy, comfort, and environmental performance, due to BGDV, BEDV and HVAC system variations in the reviewed studies.

\section{Conclusions}

The investigated literature reveals that in the BECEDO process the space organization and forming of masses is still in its infancy. On one hand, a limited number of studies explore approaches in building geometry generation without any calculating 'green 
performance' goals. On the other hand, the most advanced research using BGDV that facilitates automated energy, comfort, and environment assessment does not integrate any optimization. Among previous BECEDO work that includes BGVD optimization, approximately two-thirds of the studies employ simple shapes with a limited number of shape variables, while the remaining literature considers more sophisticated methods to modify or create building geometries during the optimization process. Efforts concentrate mostly on the performance of algorithms and methods while missing the utilization of one of the most effective architectural design factors, the space organization-based building geometry shaping to reduce energy consumption.

The BGDV's effect on energy performance is highlighted in particular review, ensuring considerable energy conservation (up to approximately $60 \%$ in combination with WWR and ORI) and further LCA savings (up to approximately $80 \%$ in combination with building envelope and active system optimization). However, in most cases, shape variables are combined with BEDVs and HVAC system variables; hence, the direct improvement potential of BGDV optimization is often difficult to determine.

In summary, a comprehensive, back and forth loop containing optimization framework that considers all the influencing parameters, objectives, and constraints in the form-finding procedure is still missing in the available literature. The outcomes of these optimization frameworks are mostly limited non-geometrical variables, complex multi-facades, oversimplified or non-constructible shapes, or confined to only a few cases and/or small buildings, which cannot effectively handle the form-finding process for designers. Due to very limited results in the BECEDO literature in terms of the variety and complexity of BGDVs, a robust quantification of these parameters needs further investigations.

It is predictable that the building geometry creation efforts of the first few studies represent a promising potential for future research. Developing strict and appropriate rules allows more comprehensive modelling of only the relevant cases, and therefore, the total search space can be 'scanned', increasing the probability of finding an optimal solution. This is important for the selected optimization method as well, since the enumerative, exhaustive brute force technique, which is the most widespread GA technology, handles all possible random points in a search space and only delivers near optimal results. Another important issue is that experienced architects, engineers, and designers who work in the building industry are currently able to deliver reasonable solutions to meet different design requirements without the need to turn to optimization tools. The knowledge of these experts has great potential in future building optimization, for instance, in defining rules to limit the search space requirements or when selecting the appropriate boundary conditions, objectives, constraints, variables, etc.

Further research is needed in the appropriate quantification of the BGDVs impact on the BECE-performance of the optimized buildings, urban districts. Additionally, future effort can invent new trend in the comprehensive and systematic generation of complete building geometry systems with involved space organization. A key feature here is the development of shape describing BGDVs, which not only determine the physical properties (mainly sizes, ratios) of the building geometry, but also provide information about the shape of the geometry in form of location parameters of the space units or coordinates of various parts of the geometry (corners, edges, etc.). This would create a link between the building shape and its geometry describing mathematical design variables to replicate the complete form of the shape with the use of BGDVs.

It is important to note that any architectural, building-related research should consider that quantifying functions or the design process would take architecture to the level of an engineering science, but architecture is more than that. The comprehensive integration of building geometry into BECEDO research offers a key step in introducing the creative, intuitive part of design into scholarly work.

Author Contributions: Conceptualization, I.K.; methodology, I.K. and Z.E.; software, K.R.H. and T.S.; validation, Z.E.; formal analysis, K.R.H. and T.S.; investigation, I.K., K.R.H., T.S. and Z.E.; resources, T.S.; data curation, K.R.H. and T.S.; writing-original draft preparation, I.K., K.R.H. and 
T.S.; writing-review and editing, I.K. and Z.E.; visualization, K.R.H.; supervision, I.K. and Z.E.; project administration, K.R.H.; funding acquisition, I.K. and Z.E. All authors have read and agreed to the published version of the manuscript.

Funding: This work was financially supported by the NKFIH (Hungarian National Agency for Research, Development and Innovation) through the following grants: [2020-4.1.1-TKP2020 Thematic Program of Excellence 2020, National Challenges Sub-program] and the [2019-2.1.11-TÉT Bilateral Scientific and Technological Cooperation].

Informed Consent Statement: Not applicable.

Data Availability Statement: Not applicable.

Acknowledgments: This research acknowledges the support received from the University of Pécs, Szentágothai János Research Centre, Hungary, through providing basic infrastructure and laboratory spaces for the Energia Design Building Technology research group.

Conflicts of Interest: The authors declare no conflict of interest. The funders had no role in the design of the study; in the collection, analyses, or interpretation of data; in the writing of the manuscript, or in the decision to publish the results.

\section{Nomenclature}

$\begin{array}{ll}\text { AC } & \text { Air-Conditioning } \\ \text { ACH } & \text { Air Change } \\ \text { ADV } & \text { Active Design Variable } \\ \text { AEC } & \text { Architecture, Engineering and Construction } \\ \text { ANN } & \text { Artificial Neural Network } \\ \text { ANOVA } & \text { Analysis of Variance } \\ \text { AR } & \text { Aspect Ratio } \\ \text { BECED } & \text { Building Energy, Comfort and Environmeltal Design } \\ \text { BECEDO } & \text { Building Energy, Comfort and Environmeltal Design Optimization } \\ \text { BEDV } & \text { Building Envelope Design Variable } \\ \text { BEO } & \text { Buiding Energy Optimization } \\ \text { BGDV } & \text { Building Geomtery Design Variables } \\ \text { BIPV } & \text { Building Integrated Photovoltaic } \\ \text { BMC } & \text { Building Modular Cell } \\ \text { BOP } & \text { Building Optimization Problem } \\ \text { CFD } & \text { Computational Fluid Dynamics } \\ \text { CMA-ES } & \text { Covariance Matrix Adaptation Evolution Strategy } \\ \text { DAE } & \text { Differential-Algebraic Equation } \\ \text { DF } & \text { Daylight Factor } \\ \text { DHW } & \text { Domestic Hot Water } \\ \text { DOE } & \text { Design Of Experiments } \\ \text { EA } & \text { Evolutionary Algorithm } \\ \text { EEF } & \text { Efficient Form-finder } \\ \text { EPSAP } & \text { Evolutionary Program for Space Allocation Program } \\ \text { ES } & \text { Evolution Strategy } \\ \text { EUI } & \text { Energy Use Intensity } \\ \text { GA } & \text { Genetic Algorithm } \\ \text { GBM } & \text { Gradient Boosting Machine learning } \\ \text { GH } & \text { GrassHopper } \\ \text { GR } & \text { Glazing Ratio (e.g., wall-window ratio) } \\ \text { GSA } & \text { Global Sensitivity Analysis } \\ \text { GUI } & \text { Graphic User Interface } \\ \text { HDE } & \text { Hybrid Differential Evolution } \\ \text { HJ } & \text { Hooke-Jeeves } \\ \text { HVAC } & \text { Heating, Ventillation, and Air Conditioning } \\ \text { LCC } & \end{array}$




$\begin{array}{ll}\text { LCCA } & \text { Life Cycle Cost Assessment } \\ \text { LCEI } & \text { Life Cycle Energy Impact } \\ \text { MDO } & \text { Multidisciplinary Design Optimization } \\ \text { MO } & \text { Multi-Objective } \\ \text { MOGA } & \text { Multi-Objective Genetic Algorithm } \\ \text { MOO } & \text { Multi-Objective Optimization } \\ \text { N, NE, E, SE, } & \text { North, North-East, East, South-East South, South-West, West, North-West } \\ \text { E, SW, W, NW } & \\ \text { NSGA } & \text { Non-dominated Sorting Genetic Algorithm } \\ \text { NV } & \text { Natural Ventilation } \\ \text { ORI } & \text { ORIentation } \\ \text { PDV } & \text { Passive Design Variable } \\ \text { PEC } & \text { Primary Energy Consumption } \\ \text { PSO } & \text { Particle Swarm Optimization } \\ \text { RC } & \text { Relative Compactness } \\ \text { SA } & \text { Simulated Annealing } \\ \text { SDA } & \text { spacial Daylight Autonomy } \\ \text { SF } & \text { Shape Factor } \\ \text { SHADE } & \text { shading } \\ \text { SHC } & \text { Stochastic Hill Climbing } \\ \text { SHGC } & \text { Solar Heat Gain Coefficient } \\ \text { SO } & \text { Single-Objective } \\ \text { STR } & \text { Structures, materials } \\ \text { TDT } & \text { Thermal Discomfort Time } \\ \text { TM } & \text { Thernal Mass } \\ \text { UDI } & \text { Useful Daylight Illuminance } \\ \text { UDV } & \text { Urban Design Varible } \\ \text { WWR } & \text { Window to Wall Ratio }\end{array}$

\section{References}

1. IEA; UNEP. 2019 Global Status Report for Buildings and Construction; UN Environment and the International Energy Agency: Nairobi, Kenya; Paris, France, 2019; Volume 224.

2. Fesanghary, M.; Asadi, S.; Geem, Z.W. Design of low-emission and energy-efficient residential buildings using a multi-objective optimization algorithm. Build. Environ. 2012, 49, 245-250. [CrossRef]

3. Cao, X.; Dai, X.; Liu, J. Building energy-consumption status worldwide and the state-of-the-art technologies for zero-energy buildings during the past decade. Energy Build. 2016, 128, 198-213. [CrossRef]

4. Pérez-Lombard, L.; Ortiz, J.; Pout, C. A review on buildings energy consumption information. Energy Build. 2008, 40, 394-398. [CrossRef]

5. Rullán-Lemke, C. ArchitekturForm \& SolarEnergie. Ph.D. Thesis, Hamburg University of Technology, Hamburg, Germany, 2009

6. Depecker, P.; Menezo, C.; Virgone, J.; Lepers, S. Design of buildings shape and energetic consumption. Build. Environ. 2001, 36, 627-635. [CrossRef]

7. AlAnzi, A.; Seo, D.; Krarti, M. Impact of building shape on thermal performance of office buildings in Kuwait. Energy Convers. Manag. 2009, 50, 822-828. [CrossRef]

8. Nguyen, A.-T.; Reiter, S.; Rigo, P. A review on simulation-based optimization methods applied to building performance analysis. Appl. Energy 2014, 113, 1043-1058. [CrossRef]

9. Shi, X.; Tian, Z.; Chen, W.; Si, B.; Jin, X. A review on building energy efficient design optimization rom the perspective of architects. Renew. Sustain. Energy Rev. 2016, 65, 872-884. [CrossRef]

10. U.S. Department of Energy. Buildings energy databook. Energy Effic. Renew. Energy Dep. 2012, 286. Available online: http: / / buildingsdatabook.eren.doe.gov / DataBooks.aspx (accessed on 17 June 2021).

11. Gupta, C. A systematic approach to optimum thermal design. Build. Sci. 1970, 5, 165-173. [CrossRef]

12. Kheiri, F. A review on optimization methods applied in energy-efficient building geometry and envelope design. Renew. Sustain. Energy Rev. 2018, 92, 897-920. [CrossRef]

13. Machairas, V.; Tsangrassoulis, A.; Axarli, K. Algorithms for optimization of building design: A review. Renew. Sustain. Energy Rev. 2014, 31, 101-112. [CrossRef]

14. Rabani, M.; Madessa, H.B.; Nord, N. Achieving zero-energy building performance with thermal and visual comfort enhancement through optimization of fenestration, envelope, shading device, and energy supply system. Sustain. Energy Technol. Assess. 2021, 44, 101020. [CrossRef]

15. Huang, B.; Gao, X.; Xu, X.; Song, J.; Geng, Y.; Sarkis, J.; Fishman, T.; Kua, H.; Nakatani, J. A Life Cycle Thinking Framework to Mitigate the Environmental Impact of Building Materials. One Earth 2020, 3, 564-573. [CrossRef] 
16. Acar, U.; Kaska, O.; Tokgoz, N. Multi-objective optimization of building envelope components at the preliminary design stage for residential buildings in Turkey. J. Build. Eng. 2021, 42, 102499. [CrossRef]

17. Al-Saadi, S.N.; Al-Jabri, K.S. Optimization of envelope design for housing in hot climates using a genetic algorithm (GA) computational approach. J. Build. Eng. 2020, 32, 101712. [CrossRef]

18. Toutou, A.; Fikry, M.; Mohamed, W. The parametric based optimization framework daylighting and energy performance in residential buildings in hot arid zone. Alex. Eng. J. 2018, 57, 3595-3608. [CrossRef]

19. Gerber, D.J.; Pantazis, E.; Wang, A. A multi-agent approach for performance based architecture: Design exploring geometry, user, and environmental agencies in façades. Autom. Constr. 2017, 76, 45-58. [CrossRef]

20. Kim, H.; Clayton, M.J. A multi-objective optimization approach for climate-adaptive building envelope design using parametric behavior maps. Build. Environ. 2020, 185, 107292. [CrossRef]

21. Abdel-Rahman, W.S.M. Thermal performance optimization of parametric building envelope based on bio-mimetic inspiration Ain Shams Eng. J. 2020, 12, 1133-1142. [CrossRef]

22. Hromada, E.; Vitasek, S.; Holcman, J.; Heralova, R.S.; Krulicky, T. Residential Construction with a Focus on Evaluation of the Life Cycle of Buildings. Buildings 2021, 11, 524. [CrossRef]

23. Liu, B.; Rodriguez, D. Renewable energy systems optimization by a new multi-objective optimization technique: A residential building. J. Build. Eng. 2020, 35, 102094. [CrossRef]

24. Palonen, M.; Hamdy, M.; Hasan, A. Mobo a new software for multi-objective building performance optimization. In Proceedings of the 13th Internationcal Conference of the IBPSA, Chambery, France, 26-28 August 2013; pp. 2567-2574.

25. Ochoa, C.; Capeluto, I.G. Strategic decision-making for intelligent buildings: Comparative impact of passive design strategies and active features in a hot climate. Build. Environ. 2008, 43, 1829-1839. [CrossRef]

26. Yu, Z.; Gou, Z.; Qian, F.; Fu, J.; Tao, Y. Towards an optimized zero energy solar house: A critical analysis of passive and active design strategies used in Solar Decathlon Europe in Madrid. J. Clean. Prod. 2019, 236. [CrossRef]

27. Li, H.; Wang, S. Coordinated optimal design of zero/low energy buildings and their energy systems based on multi-stage design optimization. Energy 2019, 189, 116202. [CrossRef]

28. Harkouss, F.; Fardoun, F.; Biwole, P. Passive design optimization of low energy buildings in different climates. Energy 2018, 165, 591-613. [CrossRef]

29. Gunay, H.B.; Ouf, M.; Newsham, G.; O’Brien, W. Sensitivity analysis and optimization of building operations. Energy Build. 2019, 199, 164-175. [CrossRef]

30. Lee, J.H. Optimization of indoor climate conditioning with passive and active methods using GA and CFD. Build. Environ. 2007, 42, 3333-3340. [CrossRef]

31. Ferdyn-Grygierek, J.; Grygierek, K. Multi-Variable Optimization of Building Thermal Design Using Genetic Algorithms. Energies 2017, 10, 1570. [CrossRef]

32. Hong, T.; Kim, J.; Lee, M. A multi-objective optimization model for determining the building design and occupant behaviors based on energy, economic, and environmental performance. Energy 2019, 174, 823-834. [CrossRef]

33. Hamdy, M. Implementation of pareto-archive NSGA-II algorithms to a nearly-zero-energy building optimisation problem. In Proceedings of the Building Simulation and Optimization Conference, Loughborough, UK, 10-11 September 2012.

34. Ke, Y.; Xie, J.; Pouramini, S. Utilization of an improved crow search algorithm to solve building energy optimization problems: Cases of Australia. J. Build. Eng. 2021, 38, 102142. [CrossRef]

35. Ilbeigi, M.; Ghomeishi, M.; Dehghanbanadaki, A. Prediction and optimization of energy consumption in an office building using artificial neural network and a genetic algorithm. Sustain. Cities Soc. 2020, 61, 102325. [CrossRef]

36. Ascione, F.; Bianco, N.; Mauro, G.M.; Napolitano, D.F. Building envelope design: Multi-objective optimization to minimize energy consumption, global cost and thermal discomfort. Application to different Italian climatic zones. Energy 2019, 174, 359-374. [CrossRef]

37. Saad, M.M.; Araji, M.T. Co-model for urban density permutations and building form optimization with high-performance energy criteria. J. Build. Eng. 2021, 43, 103109. [CrossRef]

38. Yi, Y.K.; Malkawi, A.M. Optimizing building form for energy performance based on hierarchical geometry relation. Autom. Constr 2009, 18, 825-833. [CrossRef]

39. Ciardiello, A.; Rosso, F.; Dell'Olmo, J.; Ciancio, V.; Ferrero, M.; Salata, F. Multi-objective approach to the optimization of shape and envelope in building energy design. Appl. Energy 2020, 280, 115984. [CrossRef]

40. Javanroodi, K.; Nik, V.M.; Mahdavinejad, M. A novel design-based optimization framework for enhancing the energy efficiency of high-rise office buildings in urban areas. Sustain. Cities Soc. 2019, 49, 101597. [CrossRef]

41. Gan, V.J.; Wong, H.; Tse, K.; Cheng, J.C.; Lo, I.M.; Chan, C. Simulation-based evolutionary optimization for energy-efficient layout plan design of high-rise residential buildings. J. Clean. Prod. 2019, 231, 1375-1388. [CrossRef]

42. Gratia, E.; De Herde, A. Design of low energy office buildings. Energy Build. 2003, 35, 473-491. [CrossRef]

43. Ourghi, R.; Al-Anzi, A.; Krarti, M. A simplified analysis method to predict the impact of shape on annual energy use for office buildings. Energy Convers. Manag. 2007, 48, 300-305. [CrossRef]

44. Kämpf, J.; Montavon, M.; Bunyesc, J.; Bolliger, R.; Robinson, D. Optimisation of buildings' solar irradiation availability. Sol. Energy 2010, 84, 596-603. [CrossRef] 
45. Wang, W.; Rivard, H.; Zmeureanu, R. Floor shape optimization for green building design. Adv. Eng. Inform. 2006, 20, 363-378. [CrossRef]

46. Hemsath, T.L.; Bandhosseini, K.A. Sensitivity analysis evaluating basic building geometry's effect on energy use. Renew. Energy 2015, 76, 526-538. [CrossRef]

47. Hachem, C.; Athienitis, A.; Fazio, P. Investigation of solar potential of housing units in different neighborhood designs. Energy Build. 2011, 43, 2262-2273. [CrossRef]

48. Aksoy, U.T.; Inalli, M. Impacts of some building passive design parameters on heating demand for a cold region. Build. Environ. 2006, 41, 1742-1754. [CrossRef]

49. Waibel, C.; Evins, R.; Carmeliet, J. Co-simulation and optimization of building geometry and multi-energy systems: Interdependencies in energy supply, energy demand and solar potentials. Appl. Energy 2019, 242, 1661-1682. [CrossRef]

50. Fang, Y.; Cho, S. Design optimization of building geometry and fenestration for daylighting and energy performance. Sol. Energy 2019, 191, 7-18. [CrossRef]

51. Hemsath, T.L.; Bandhosseini, K.A. Building Design with Energy Performance as Primary Agent. Energy Procedia 2015, 78, 3049-3054. [CrossRef]

52. Sibenik, G.; Kovacic, I. Interpreted open data exchange between architectural design and structural analysis models. J. Inf. Technol. Constr. 2021, 26, 39-57. [CrossRef]

53. Mert, Y.; Saygın, N. Energy efficient building block design: An exergy perspective. Energy 2016, 102, 465-472. [CrossRef]

54. Granadeiro, V.; Duarte, J.; Correia, J.R.; Leal, V. Building envelope shape design in early stages of the design process: Integrating architectural design systems and energy simulation. Autom. Constr. 2013, 32, 196-209. [CrossRef]

55. Rodrigues, E.; Fernandes, M.; Soares, N.; Gomes, Á.; Gaspar, A.R.; Costa, J.J. The potential impact of low thermal transmittance construction on the European design guidelines of residential buildings. Energy Build. 2018, 178, 379-390. [CrossRef]

56. Javanroodi, K.; Mahdavinejad, M.; Nik, V.M. Impacts of urban morphology on reducing cooling load and increasing ventilation potential in hot-arid climate. Appl. Energy 2018, 231, 714-746. [CrossRef]

57. Cao, X.; He, Z.; Pan, Y. Automated design of house-floor layout with distributed planning. Comput. Des. 1990, $22,213-222$. [CrossRef]

58. Elezkurtaj, T.; Franck, G. Algorithmic support of creative architectural design. Organization 2002, 2, 16. Available online: http:/ / www.iemar.tuwien.ac.at/wp-content/uploads/2011/12/umbau19.pdf (accessed on 17 June 2021).

59. Francisco, J.; Costa, R.; Doc, P.; Manuel, V.; Murtinho, B. Development of an Algorithm Which Generates Functional Floor Plans for Residential Buildings Based on Modular Construction. Ph.D. Thesis, University in Coimbra, Coimbra, Portugal, 2015.

60. Guo, Z.; Li, B. Evolutionary approach for spatial architecture layout design enhanced by an agent-based topology finding system. Front. Arch. Res. 2017, 6, 53-62. [CrossRef]

61. D'Cruz, N.A.; Radford, A.D. A multicriteria model for building performance and design. Build. Environ. 1987, 22, 167-179. [CrossRef]

62. Hauglustaine, J.M.; Lema, S.A. Interactive Tool Aiding to Optimise The Building Envelope During The Sketch Design. In Proceedings of the Seventh International IBPSA Conference (BS2001), Rio de Janeiro, Brazil, 13-15 August 2001.

63. Jedrzejuk, H.; Marks, W. Optimization of shape and functional structure of buildings as well as heat source utilization. Basic theory. Build. Environ. 2002, 37, 1379-1383. [CrossRef]

64. Coley, D.A.; Schukat, S. Low-energy design: Combining computer-based optimisation and human judgement. Build. Environ. 2002, 37, 1241-1247. [CrossRef]

65. Caldas, L.G.; Norford, L.K. Genetic Algorithms for Optimization of Building Envelopes and the Design and Control of HVAC Systems. J. Sol. Energy Eng. 2003, 125, 343-351. [CrossRef]

66. Sisk, G.M.; Miles, J.C.; Moore, C.J. Designer Centered Development of GA-Based DSS for Conceptual Design of Buildings. J. Comput. Civ. Eng. 2003, 17, 159-166. [CrossRef]

67. Wang, W.; Zmeureanu, R.; Rivard, H. Applying multi-objective genetic algorithms in green building design optimization. Build. Environ. 2005, 40, 1512-1525. [CrossRef]

68. Choudhary, R.; Malkawi, A.; Papalambros, P. Analytic target cascading in simulation-based building design. Autom. Constr. 2005, 14, 551-568. [CrossRef]

69. Malkawi, A.M.; Srinivasan, R.S.; Yi, Y.K.; Choudhary, R. Decision support and design evolution: Integrating genetic algorithms, CFD and visualization. Autom. Constr. 2005, 14, 33-44. [CrossRef]

70. Adamski, M. Optimization of the form of a building on an oval base. Build. Environ. 2007, 42, 1632-1643. [CrossRef]

71. Geyer, P. Component-oriented decomposition for multidisciplinary design optimization in building design. Adv. Eng. Inform. 2009, 23, 12-31. [CrossRef]

72. Flager, F.; Welle, B.; Bansal, P.; Soremekun, G.; Haymaker, J. Multidisciplinary process integration and design optimization of a classroom building. Electron. J. Inf. Technol. Constr. 2009, 14, 595-612.

73. Bucking, S.; Athienitis, A.; Zmeureanu, R. An Optimization Methodology to Evaluate the Effect Size of Incentives on Energy-cost Optimal Curves. In Proceedings of the Thirteenth International IBPSA Conference, Chambéry, France, 26-28 August 2008; pp. 1844-1851.

74. Nguyen, A.T.; Reiter, S. Passive designs and strategies for low-cost housing using simulation-based optimization and different thermal comfort criteria. J. Build. Perform. Simul. 2013, 7, 68-81. [CrossRef] 
75. Xu, J.; Kim, J.-H.; Hong, H.; Koo, J. A systematic approach for energy efficient building design factors optimization. Energy Build. 2014, 89, 87-96. [CrossRef]

76. Yu, W.; Li, B.; Jia, H.; Zhang, M.; Wang, D. Application of multi-objective genetic algorithm to optimize energy efficiency and thermal comfort in building design. Energy Build. 2015, 88, 135-143. [CrossRef]

77. Ascione, F.; Bianco, N.; Mauro, G.M.; Vanoli, G.P. A new comprehensive framework for the multi-objective optimization of building energy design: Harlequin. Appl. Energy 2019, 241, 331-361. [CrossRef]

78. Kiss, B.; Szalay, Z. Modular approach to multi-objective environmental optimization of buildings. Autom. Constr. 2020, 111, 103044. [CrossRef]

79. Zou, Y.; Zhan, Q.; Xiang, K. A comprehensive method for optimizing the design of a regular architectural space to improve building performance. Energy Rep. 2021, 7, 981-996. [CrossRef]

80. Yigit, S. A machine-learning-based method for thermal design optimization of residential buildings in highly urbanized areas of Turkey. J. Build. Eng. 2021, 38, 102225. [CrossRef]

81. Wang, S.; Yi, Y.K.; Liu, N. Multi-objective optimization (MOO) for high-rise residential buildings' layout centered on daylight, visual, and outdoor thermal metrics in China. Build. Environ. 2021, 205, 108263. [CrossRef]

82. Lin, B.; Chen, H.; Yu, Q.; Zhou, X.; Lv, S.; He, Q.; Li, Z. MOOSAS-A systematic solution for multiple objective building performance optimization in the early design stage. Build. Environ. 2021, 200, 107929. [CrossRef]

83. McKeen, P.; Fung, A.S. The Effect of Building Aspect Ratio on Energy Efficiency: A Case Study for Multi-Unit Residential Buildings in Canada. Buildings 2014, 4, 336-354. [CrossRef]

84. Elshafei, G.; Vilčeková, S.; Zeleňáková, M.; Negm, A.M. An Extensive Study for a Wide Utilization of Green Architecture Parameters in Built Environment Based on Genetic Schemes. Buildings 2021, 11, 507. [CrossRef]

85. Ansah, M.K.; Chen, X.; Yang, H. Two-Stage Lifecycle Energy Optimization of Mid-Rise Residential Buildings with BuildingIntegrated Photovoltaic and Alternative Composite Façade Materials. Buildings 2021, 11, 642. [CrossRef]

86. Duart, P.J.; Rocha, J. A Grammar for the Patio Houses of the Medina of Marrakech Towards a Tool for Housing Design in Islamic Contexts. 2006. Available online: http://cumincad.scix.net/data/works/att/2006_860.content.pdf (accessed on 17 June 2021).

87. Guerritore, C.; Duarte, J. Design Computing and Cognition'12; Springer: Berlin/Heidelberg, Germany, 2015. [CrossRef]

88. Tuhus-Dubrow, D.; Krarti, M. Genetic-algorithm based approach to optimize building envelope design for residential buildings. Build. Environ. 2010, 45, 1574-1581. [CrossRef]

89. Bichiou, Y.; Krarti, M. Optimization of envelope and HVAC systems selection for residential buildings. Energy Build. 2011, 43, 3373-3382. [CrossRef]

90. Ullrich, T.; Silva, N.; Eggeling, E.; Fellner, D.W. Generative modeling and numerical optimization for energy efficient buildings. In Proceedings of the IECON 2013 - 39th Annual Conference of the IEEE Industrial Electronics Society, Vienna, Austria, 10-13 November 2013; IEEE: New York, NY, USA, 2013; pp. 4756-4761. [CrossRef]

91. Kämpf, J.H.; Robinson, D. Optimisation of building form for solar energy utilisation using constrained evolutionary algorithms. Energy Build. 2010, 42, 807-814. [CrossRef]

92. Duarte, J.P.; Rocha, J.M.; Soares, G.D. Unveiling the structure of the Marrakech Medina: A shape grammar and an interpreter for generating urban form. Artif. Intell. Eng. Des. Anal. Manuf. 2007, 21, 317-349. [CrossRef]

93. Michalek, J.; Choudhary, R.; Papalambros, P. Architectural layout design optimization. Eng. Optim. 2002, 34, 461-484. [CrossRef]

94. Junghans, L.; Darde, N. Hybrid single objective genetic algorithm coupled with the simulated annealing optimization method for building optimization. Energy Build. 2015, 86, 651-662. [CrossRef]

95. Si, B.; Tian, Z.; Jin, X.; Zhou, X.; Tang, P.; Shi, X. Performance indices and evaluation of algorithms in building energy efficient design optimization. Energy 2016, 114, 100-112. [CrossRef]

96. ANSI/ASHRAE Standard 55-2010; Thermal Environmental Conditions for Human Occupancy. American Society of Heating, Refrigerating and Air-Conditioning Engineers, Inc.: Atlanta, GA, USA, 2004. Available online: http://arco-hvac.ir/wp-content/ uploads/2015/11/ASHRAE-55-2010.pdf(accessed on 25 June 2021).

97. Juan, Y.-K.; Gao, P.; Wang, J. A hybrid decision support system for sustainable office building renovation and energy performance improvement. Energy Build. 2010, 42, 290-297. [CrossRef]

98. Gero, J.S.; D'Cruz, N.; Radford, A.D. Energy in context: A multicriteria model for building design. Build. Environ. 1983, 18, 99-107. [CrossRef]

99. Eisenhower, B.; O’Neill, Z.; Narayanan, S.; Fonoberov, V.A.; Mezić, I. A methodology for meta-model based optimization in building energy models. Energy Build. 2011, 47, 292-301. [CrossRef]

100. Chen, J.; Gao, X.; Hu, Y.; Zeng, Z.; Liu, Y. A meta-model-based optimization approach for fast and reliable calibration of building energy models. Energy 2019, 188, 116046. [CrossRef] 